\title{
Geographic variation in reaction norms of phenological traits in the greater duckweed, Spirodela polyrhiza
}

By

Harry W. Hitsman

A thesis submitted to the Faculty of Graduate and Postdoctoral Affairs in partial fulfillment of the requirements for the degree of

Master of Science

In

Biology

Carleton University

Ottawa, Ontario

(C) 2018

Harry Hitsman 


\section{Abstract}

Variability is a ubiquitous feature of natural environments. Organisms can adapt to this through several methods such as adaptive phenotypic plasticity, changes in phenotype in response to reliable cues predicting fitness outcomes across environments, and bet hedging, the maximization of geometric mean fitness. The greater duckweed Spirodela polyrhiza is an ideal system to study the evolution of these strategies. Phenology of production of overwintering structures called turions, a phenotypically plastic trait that can prevent reproductive failure, is thus vital to fitness. Despite clonal reproduction, offspring show phenotypic variability in both turion phenology and size, mediated through the order in which they are produced, suggesting the expression of diversification bet hedging. Here I use S. polyrhiza populations collected from a latitudinal gradient to study how life-history traits evolve in response to variable environments. I make two hypotheses; first, I hypothesized that reaction norms in turion formation differ across latitudes due to differences in season length and environmental predictability. Second, I hypothesised that populations from northern latitudes would trade off offspring size for number to allow for greater diversification potential at northern latitudes where environments are expected to be more variable. I found support for the first hypothesis, showing that reaction norms in turion phenology do differ such that turions are produced earlier at higher latitudes under warmer, but not colder experimental treatments. I was unable to evaluate my second hypothesis due to premature frond mortality but did show that, while size was only weakly correlated with latitude, significant differences between some populations were present, suggesting offspring size is affected more by local environmental conditions that those that are correlated with latitude. 


\section{Acknowledgments}

There are a number of people I would like to thank for their support and assistance. First and foremost, I would like to thank my supervisor Dr. Andrew Simons for all his support throughout my master's degree and for his expert advice that was crucial to my research. Under his supervision, I have acquired many invaluable skills and I am grateful for everything he has done for me in my time at Carleton. I would also like to thank my advisory committee, Dr. Tom Sherratt and Dr. Risa Sargent for their guidance and helpful comments. I would like to thank Dr. Catherine Cullingham and Dr. Naomi Cappuccino for serving as external examiner and chair for my thesis defence. I acknowledge the financial support I have received from Andrew's NSERC Discovery grant as well as financial support I received from the Faculty of Graduate Studies.

This thesis would not have been possible without the assistance of everyone who assisted in duckweed collecting. I would like to thank Dr. Lyn Gettys, Dr. James Hood, Andrew Boyce Reeve, Dr. Nic Kooyers and Dr. Michele Guidone for their assistance in sample collection. In addition to this, I would also like to thank Tina Stimmler, Cindy Hubbard, Michelle Shooter and Ann Gallagher, who went above and beyond in assisting me with sample certification for importation. I am grateful for the gracious assistance of Kousay Kojan, Grace Simonds and Vivienne Seymour in the lab.

Thank you to all the members of the Simon's lab for their support throughout my time here. Thank you in particular to Shravan Ram, Lina Wen, Winston Campeau and Mahmoud El Saadi for their help around the lab and many moments I will never forget. Thank you also to 
Riley Morris for his knowledge and expertise with duckweed that helped me greatly during this program.

I would like to thank my parents, Sarah, Ted, particularly in helping me with the main part of sampling collecting, and my siblings Nick and Charlotte for all their support throughout my master's. I would also like to thank my aunt and uncle, John and Liz, for giving me a place to stay in my first year here. Finally, I am grateful for the love and support of my girlfriend, Teigan Goldsmith, for everything she has done throughout this program, from assisting with experiments to motivating me when I needed it most. 


\section{Table of Contents}

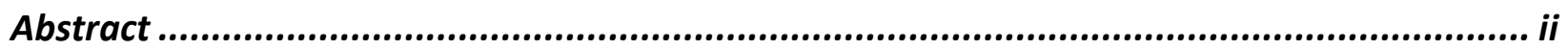

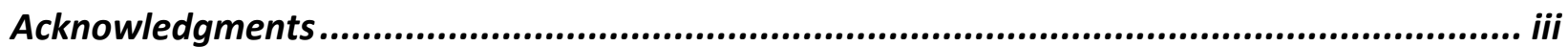

List of Appendices.................................................................................................................... vi

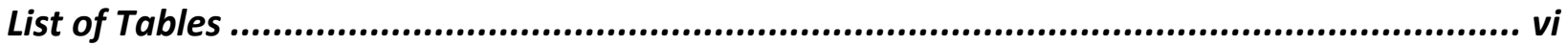

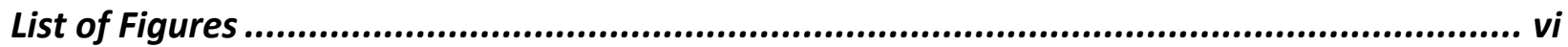

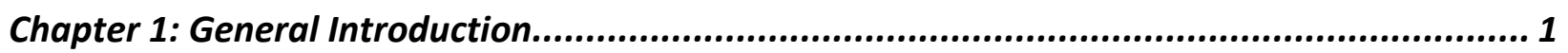

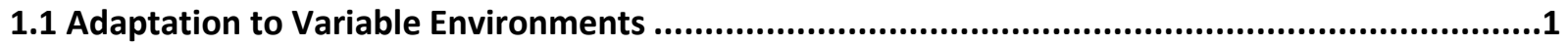



1.3 Study System .....................................................................................................................

Chapter 2. Latitudinal variation in norms of reaction of phenology in the greater duckweed Spirodela polyrhiza .............................................................................................................. 7

2.1 Introduction .......................................................................................................................

2.2 Methods ...........................................................................................................................12

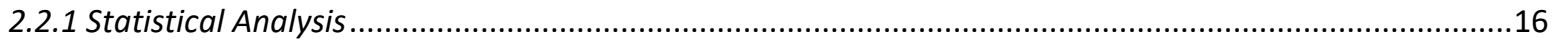

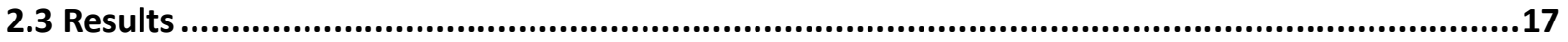

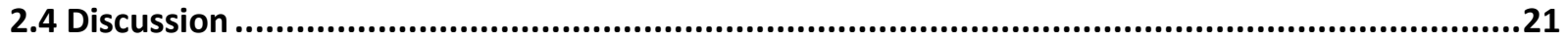

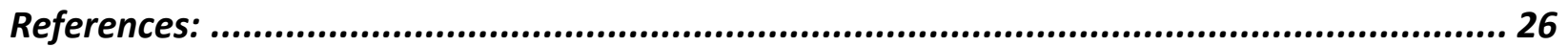

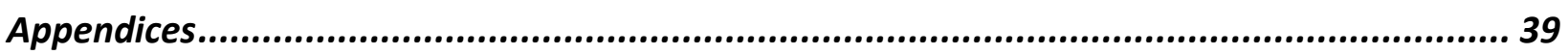

Appendix A. Offspring size and number experiment.................................................................39

Appendix B. Initial thermogradient run.............................................................................................41 


\section{List of Appendices}

Appendix A Offspring size and number experiment

Appendix $B \quad$ Initial thermogradient run

List of Tables

Table 2.1, Likelihood ratio tests for the effect of each variable on first turion birth order. Each row represents the removal of a variable from the full model.

\section{List of Figures}

Figure 2.1. S. polyrhiza collection locations. Fronds were collected from 7 latitudes with 2 populations per latitude with the exception of Georgia (1 population) for 13 total populations.

Figure 2.2. Schematic of thermogradient incubator. A heater and chiller circulate warm and cold water through the underlying aluminum block at opposite ends to produce a temperature gradient in the aquatic chamber above. Pumps circulate water to maintain constant temperature within each section of the aquatic chamber. Fronds were placed in tubes in each temperature section.

Figure 2.3. Effect of temperature and latitude on log transformed first turion birth order for 13 populations across seven latitudes. $R^{2}$ value is from 2 factor ANCOVA of main effects with interaction for illustration purposes.

Figure 2.4. Effect of temperature and latitude on time to first turion (days). $R^{2}$ value is from two factor second degree polynomial ANCOVA with interactions for illustration purposes.

Figure 2.5. Log first turion birth order (a) and days to first turion (b) for both Florida populations, showing reaction norm differentiation between these populations.

Figure A1. Correlation between latitude and offspring size in mother birth order 1 (a) and mother birth order 5 (b) both at $25^{\circ} \mathrm{C}$. No significant relationships were observed for any other birth orders at either temperature.

Figure A2. Average frond length for each population.

Figure A3. Schematic of thermogradient set up for first run of experiment. Yellow highlighting shows only temperature at which differentiation in turions production was observed.

Figure A4. Proportion of offspring produced that were turions for each latitude at three temperatures. 
Figure A5. Logistic regression of turion production probability vs. latitude at $16^{\circ} \mathrm{C}$. Y-axis indicates whether each frond produced a turion or not. 


\section{Chapter 1: General Introduction}

\subsection{Adaptation to Variable Environments}

Natural environmental variability is a constant (Aesawy \& Hasanean, 1998; Jones \& Briffa, 1992; Liu et al., 2006; Yoshifuji et al., 2006) and has profound effects on fitness. These effects can be direct (Bozinovic et al., 2011; Siddiqui et al., 1973); for example, exposure to variable or constant temperature environments in Drosophila melanogaster causes differences in the ability to cope with stress (Bozinovic et al., 2011). Environmental variability can also have evolutionary effects, such as environmental mismatches caused by climate change (Edwards \& Richardson, 2004; Jones \& Cresswell, 2010; Post \& Forchhammer, 2008) highlighting the difficulties in adapting to variable environments. Because of these effects, environmental variability should be considered when studying the evolution of life-history and phenological traits. In this thesis, I use greater duckweed Spirodela polyrhiza populations collected from a latitudinal gradient to empirically address how life-history and phenological traits evolve in variable environments. While many studies have shown genetic differentiation across latitudes, few have used multiple environments to determine how different populations have evolved in response to environmental gradients.

Adaptation to variable environments can take multiple forms including adaptive phenotypic plasticity (DeWitt \& Scheinert, 2004; Ghalambor et al., 2007; Pigliucci, 2001; Via et al., 1995) and bet hedging (Seger \& Brockmann, 1987; Simons, 2011). Adaptive phenotypic plasticity, the production of multiple phenotypes by a single genotype in different environments, is expected to evolve when this environmental change is predictable (DeWitt et al., 1998; Reed et al., 2010) and occurs through phenotypic changes that are correlated with 
fitness across environments (Riessen \& Trevett-Smith, 2009; Schmitt et al., 1995; Stabell et al., 2003). The evolution of phenotypic plasticity is constrained by many factors however, including when environmental cues do not predict fitness in future environmental states (Van Kleunen \& Fischer, 2005).

Bet hedging, on the other hand, evolves in situations when this environmental change is unpredictable (Childs et al., 2010; Graham et al., 2014; Seger \& Brockmann, 1987; Simons, 2011) and the evolution of adaptive plasticity is constrained. Bet hedging maximizes long term geometric-mean fitness at the expense of short-term fitness (Simons, 2011) and can occur in two ways. Conservative bet hedging is the production of a single risk averse phenotype (Childs et al., 2010; Rees et al., 2006; Simons, 2011); for example, early flowering phenology is thought to prevent reproductive failure when timing of season termination is unpredictable (Simons \& Johnston, 2003). Diversification bet hedging involves spreading risk over phenotypically diverse offspring that ensures success of some (Childs et al., 2010; Einum \& Fleming, 2004; Graham et al., 2014; Simons, 2011). For example, diversification in cyst hatching time in Anostraca shrimp prevents reproductive failure in pools with unpredictable filling and drying durations (Simovich \& Hathaway, 1997). While there has been recent interest in bet hedging (García-Roger et al., 2017; Graham et al., 2014; Gremer \& Venable, 2014; Simons, 2011; Tarazona et al., 2017), more research is needed to explore differences in bet-hedging strategies between populations in areas where the degree of environmental variability differs.

\subsection{Use of Latitudinal Gradients}

Latitudinal gradients have long been used to study how traits evolve in different environments. Several environmental factors are correlated with latitude. These include 
temperature, light intensity, season length and environmental variability (Caldwell et al., 1980; Rind, 1998; Xu et al., 2017). Latitudinal gradients have been used to study trait differentiation in a variety of organisms including plants (Debieu et al., 2013; Kollmann \& Banuelos, 2004; B. Li et al., 1998; Olsson \& Agren, 2002), insects (Land et al., 1999; Lankinen et al., 2013; Mousseau \& Roff, 1989), fish (Fleming and Gross, 1990) and amphibians (Laugen et al., 2003).

Evidence of genetic differentiation in life-history traits across latitudes is strong (Kollmann \& Banuelos, 2004; Laugen et al., 2003; B. Li et al., 1998; Olsson \& Agren, 2002; Parsons \& Joern, 2014). Flowering time, for example, occurs earlier at higher latitude populations under common garden conditions (Kollmann \& Banuelos, 2004; Olsson \& Agren, 2002). There has also been research into offspring size and number output strategies across latitudes (Fleming \& Gross, 1990; Kokita, 2003; Parry, Goyer, \& Lenard, 2001; Payne, 1976). Increased allocation to offspring number at northern latitudes and size at southern latitudes has been found in fish (Fleming and Gross, 1990; Kokita 2003) while the opposite was found in caterpillars (Parry, Goyer, \& Lenhard, 2001). Others have found no strong trends (Ji \& Wang, 2005; Payne, 1976). Many have shown that in mammals (Ashton et al., 2000; Meiri \& Dayan, 2003) and birds (Ashton, 2002; Meiri \& Dayan, 2003) there is a positive correlation between latitude and body/offspring size. Most reptile species, however are smaller at higher latitudes (Ashton \& Feldman, 2003). In plants, there is strong evidence for a negative correlation between seed mass and latitude (Aizen \& Woodcock, 1992; Moles et al., 2007; Moles \& Westoby, 2003). This suggests that latitudinal trends in offspring size and number are highly variable between taxa and that many factors interact to determine evolutionary outcomes. 
Less well understood than trends in mean trait values is how phenotypic plasticity and bet-hedging strategies vary across latitudes. Some studies show genetic differentiation in trait plasticity across latitudes in both animals (Klepsatel et al., 2013; Rohner et al., 2019) and plants (Simons, 2014; Toftegaard et al., 2016). There has been recent interest in plasticity of morphological traits in insects with studies showing that reaction norms in several traits show latitudinal differentiation (Gilchrist \& Huey, 2004; Kingsolver et al., 2007; Morin et al., 1999). Plasticity in developmental time also shows divergence across latitudes (Kingsolver et al., 2007; Merilai et al., 2000; Stillwell \& Fox, 2005). Very little research has analysed geographical variation in bet-hedging strategies. One study has shown greater offspring variability (Chen, Friesen, et al., 2018) - a trait often associated with diversification bet hedging - at higher altitudes where environmental unpredictability is higher. Since diversification bet-hedging strategies are characterized by the production of variable offspring, increased offspring production would be expected at higher latitudes under greater environmental unpredictability (Simons, 2007).

\subsection{Study System}

Here, I use the greater duckweed Spirodela polyrhiza to investigate the evolution of lifehistory and phenological traits across latitudes with emphasis on phenotypic plasticity and bet hedging. S. polyrhiza is an aquatic plant that floats on the surface of stagnant bodies of water. It has been used extensively in physiological (Bieleski, 1968; Ley et al., 1997), environmental remediation (Ansari \& Khan, 2009) and toxicological studies (Caicedo et al., 2000; Doğanlar, 2013; Qiao et al., 2012; Su et al., 2017). Recently, it and other duckweed species have emerged 
as a useful system in evolutionary ecological research (Barks \& Laird, 2016; Barks et al., 2018; Laird \& Barks, 2018; Mejbel \& Simons, 2018; Morris, 2018).

S. polyrhiza is among the fastest reproducing flowering plants with a generation time of approximately two days (Ziegler et al., 2015) and high offspring output making it useful in studying life-history evolution (Laird \& Barks, 2018). It also has a wide distribution (Hillman, 1961) and can be used to test for geographic variation in a variety of traits. S. polyrhiza produces almost entirely clonally through vegetative propagation (Wang et al., 2014a) so genetically identical plants can be replicated across treatments to allow assessment of phenotypically plastic traits.

S. polyrhiza produces structures called turions prior to winter that allow the organism to survive water body freezing. Turions reactivate in the spring and give rise to normal frond production (Hillman, 1961). The timing of turion production is thus crucial to fitness since late turion production may result in reproductive failure if turions are not produced before water body freeze over. Early turion production, alternatively, is detrimental if turions are produced at the expense of fronds when growing conditions are favorable. Thus, a trade-off between early turion formation sacrificing offspring production and late turion production potentially risking reproductive failure exists. Turion production is phenotypically plastic, with its initiation induced by factors including cool temperatures associated with the onset of winter (Mejbel \& Simons, 2018). Despite being clonally produced, both turion phenology and offspring size are variable among offspring (Barks \& Laird, 2016; Mejbel \& Simons, 2018). This is mediated through the order in which offspring are produced such that late birth order offspring are smaller (Barks and Laird, 2016) and produce turions earlier in their lifetime than early birth 
order offspring (Mejbel and Simons, 2018). This has led to the hypothesis that variation in turion phenology across clonally produced offspring is a bet-hedging strategy to prevent reproductive failure under unpredictable growing season termination (Mejbel \& Simons, 2018).

Here my goal is to study geographic variation in life-history traits in S. polyrhiza. Specifically, I predict that thermal reaction norms in turion formation will differ across a latitudinal gradient, since both season length and environmental predictability differ across this gradient (Liu et al., 2006; Yoshifuji et al., 2006). I was also interested in differences in offspring number and size across latitudes as well as a starting point to determine if bet-hedging strategies vary geographically. I predicted that at higher latitudes, higher offspring output would be favoured, which may be traded off with offspring size. This is because of a negative correlation between latitude and environmental predictability, potentially favoring a bet-hedging strategy. Due to unexpected frond mortality however, I was unable to answer this question. Though I did gather some data on offspring size, rather than include this work as a separate chapter, I report data and findings in appendix A.

This thesis will provide insight into how phenotypically plastic and potential bet-hedging traits evolve in variable environments. While it is well established that adaptive phenotypic plasticity is vital in adaptation to variable environments (Charmantier et al., 2008; Reed et al., 2010; Simons, 2011; Van Kleunen \& Fischer, 2005) evidence of geographical variation in norms of reaction is lacking. 


\section{Chapter 2. Latitudinal variation in norms of reaction of phenology in the greater duckweed Spirodela polyrhiza}

\subsection{Introduction}

Natural environments vary temporally in factors that may affect fitness such as in season length (Yoshifuji et al., 2006), precipitation (Liu \& Yin, 2000) and temperature (Aesawy \& Hasanean, 1998; Jones \& Briffa, 1992). Response to such environmental variation may take several forms, including adaptive tracking, adaptive plasticity, and the evolution of bet-hedging traits. Phenotypic plasticity, the production of multiple phenotypes by a single genotype in different environments, can be adaptive or non-adaptive. Non-adaptive plasticity is generally interpreted as a passive response to environmental differences or stresses (Ghalambor et al., 2007; Van Kleunen \& Fischer, 2005). For example, plasticity in several life-history traits in Arabidopsis thalinana in response to plant density provides no fitness benefit (Dorn et al., 2000). Adaptive plasticity, when phenotypic change occurs in the same direction as the fitness optimum (Ghalambor et al., 2007), requires environmental cues that reliably indicate how a phenotype will affect fitness under a change in the environment (DeWitt et al., 1998; Reed et al., 2010; Simons, 2011). For example, the development of neck spines in response to predator alarm cues in Daphnia spp., reduces risk of predation (Riessen \& Trevett-Smith, 2009; Stabell et al., 2003), and stem elongation in Brassica in response to shading provides a fitness advantage over plants with blocked elongation pathways (lacking a plastic response) (Schmitt et al., 1995).

Although plasticity may be expressed in any kind of trait (morphological, physiological, behavioural etc.), phenological traits are especially subject to plastic expression in both plants and animals (Anderson et al., 2012; Charmantier et al., 2008; Merilai et al., 2000; Quinn \& Wetherington, 2002; Vitasse et al., 2010). For example, shifts in seed dormancy are initiated by 
a variety of cues that indicate quality of growing conditions (Baskin et al., 1999; Footitt et al., 2013; Platenkamp, 1991; Schütz et al., 2002; Sultan, 1996), and flowering time is plastic to temperature and timing of snowmelt (Anderson et al., 2012, 2011).

Environmental variation, most notably when it is unpredictable, also selects for bethedging strategies (Childs et al., 2010; Graham et al., 2014; Seger \& Brockmann, 1987; Simons, 2011). Bet hedging may be conservative, in which a single 'safe' phenotype is produced (Rees et al., 2006; Simons \& Johnston, 2003; Simons, 2011) or bet hedging may be effected through diversification in which the production of multiple phenotypes suited to different environments are produced, ensuring success of at least a subset (Childs et al., 2010; Einum \& Fleming, 2004; Graham et al., 2014; Simons, 2009; Simons, 2011). Because environmental variation is composed of both predictable and unpredictable components, the expression of both plasticity and bet-hedging can be expected (Donaldson-Matasci et al., 2013; Simons, 2014).

The greater duckweed Spirodela polyrhiza (L.) Schleiden is especially well suited to study the role of phenotypic plasticity and diversification in evolution of life-history traits: S. polyrhiza reproduces asexually almost exclusively, through budding of offspring fronds from meristematic “pockets”(Lemon \& Posluszny, 2000). Overwintering buds called turions (Hillman, 1961; Krajnčič \& Devidé, 1979; Krajnčič \& Slekovec-Golob, 1991; Wang et al., 2014a), are produced through vegetative propagation (Wang et al., 2014a) from the same meristematic tissue as normal fronds. These starch-rich structures sink to the bottom of water bodies and remain in a dormant state until favourable conditions resume (Appenroth et al., 1996; Jacobs, 1947). Production of turions is critical to overwinter survival in locations that regularly experience freezing conditions (Jacobs 1947). 
Turion formation in S. polyrhiza is a plastic trait that may be influenced by several factors, and is known to be initiated by exposure to cold temperature (Mejbel \& Simons, 2018). While it is clear that phenotypic plasticity, at least in part, controls the timing of turion production, the expression of diversification bet hedging is expected to as well. Diversification in this clonal organism is potentially mediated through maternal effects. The birth order of mother fronds, here meaning the order in the sequence of fronds at which the particular mother frond was originally produced, has been shown to consistently affect the timing of turion production, with later birth order fronds producing turions sooner (Mejbel \& Simons, 2018). This difference in timing may thus reflect a diversification bet-hedging strategy, as offspring of a single genotype exhibit a range of phenotypes that depend on their birth order. The use of a latitudinal gradient can be used to study the evolutionary divergence of phenology in this trait, in that we expect differences in timing of turion production, potentially due to both plasticity and bet hedging.

Latitudinal gradients have often been used to infer and test for differentiation in optimal life-history traits (Debieu et al., 2013; Fleming \& Gross, 1990; Kollmann \& Banuelos, 2004; Land et al., 1999; Laugen et al., 2003; Li et al., 1998; Mousseau \& Roff, 1989; Olsson \& Agren, 2002; Santamaria et al., 2003). Studies have shown genetic differentiation in flowering time such that flowering occurs earlier at higher latitudes/altitudes suggesting different optimal flowering time in different locations (Olsson and Agren 2002; Kollmann and Banuelos 2004; Wagner and Simons, 2009). Similar trends have been observed for timing of diapause in Drosophila montana (Tyukmaeva et al., 2011) and time to bud set and leaf abscission in Populus tremula (Hall et al., 2007). Environmental gradients exist along latitudes, differing in a number of factors including 
temperature, light intensity, season length and environmental variability (Caldwell et al., 1980; Rind, 1998; Xu et al., 2017). Since optimal life-history strategies may vary across environments, it is expected that strategies will differ along latitudinal clines. This makes the use of latitudinal clines a convenient method to study how life-history traits evolve in different environments. Latitudinal differences in trait values is well established, and there has been significant recent interest also in the evolution of plasticity across latitudinal and altitudinal gradients (Ayrinhac et al., 2004; Li et al., 2016; Molina-Montenegro et al., 2012; Overgaard et al., 2011; Záhorská et al., 2017). Despite this, little is known about how norms of reaction differ geographically, particiularly in phenological traits. Some studies have reported genetic differentiation in plastic morphological traits across latitudes or altitudes (Klepsatel et al., 2013; Rohner et al., 2019b), where nonsignificant latitude/altitude-by-environment interactions suggest that, while there is genetic differentation, reaction norms do not differ. However, geographical differences in reaction norms are well established in morphological traits in insects (Gilchrist \& Huey, 2004; Kingsolver et al., 2007; Morin et al., 1999). Studies in plants have shown a positive correlation between degree of plasticity and distance away from the equator (Li et al., 2016; Molina-Montenegro et al., 2012) while others have shown this correlation is weak or absent (Kellermann et al., 2018; Overgaard et al., 2011).

Few studies have shown differing reaction norms in phenological traits. Toftegaard et al. (2016) investigated flowering phenology along a latitudinal gradient, showing a significant interaction between latitude and temperature in just one of five species. Notably, Kingsolver et al. (2007) and Stillwell \& Fox (2005) showed reaction norm differentiation in development time between low and high latitude/altitude populations in insects; also northern and southern 
populations of frogs react differently to differing food and temperature environments suggesting reaction norm differentiation (Merilai et al., 2000). In these three studies, only 2 latitudes/altitudes are examined, making it difficult to draw strong conclusions about the relationship between latitudes and reaction norms. There is evidence, however, of reaction norm differentiation in development time in butterflies (Posledovich et al., 2014) and damselflies (Śniegula et al., 2012) across three latitudes. Nevertheless, more research is needed to understand how reaction norms of phenological traits evolve in different environments. This will be addressed by examining differentiation across latitudes in phenological reaction norms of turion production in S. polyrhiza.

Here, S. polyrhiza collected from thirteen populations from across seven latitudes ranging from northern Ontario to southern Florida were used to test for geographical differences in reaction norms of turion production. We hypothesized that that reaction norms would differ, with turion production at northern latitudes occurring earlier (e.g. at a lower birth order) because season length is both shorter and less predictable (Naya et al., 2008; Xu et al., 2017). A gradient using temperatures known to initiate turion production was used to assess reaction norms. Descendants of plants from each population were positioned at each temperature along the gradient, and the propensity of each population to produce turions along this gradient was measured. Thus, the effects of phenotypic plasticity and genetic differentiation were simultaneously tested, and this design allowed us to determine whether reaction norms differ across latitudes. A finding of population differentiation would motivate future evaluation of the adaptive significance of these differences, as well as investigation of underlying genetic mechanisms of reaction norm differentiation. 


\subsection{Methods}

Fronds were collected along a latitudinal gradient of approximately $2300 \mathrm{~km}$ in the eastern United States and Canada from 7 main locations or latitudes (Figure 2.1) in June/July of 2018. I collected directly from every latitude with the exception of Florida. These two populations were collected by researchers from the area. For American populations, phytosanitary certificates were obtained prior to export into Canada. Two replicate populations were collected from each geographical location, with the exception of Georgia in which only a single population could be located. Replicates were collected from different waterbodies/systems to allow inferences about differences among latitudes, and to maximize the probability of sampling different genotypes. Because it is possible that traits of interest respond to pond size, fronds were collected from at least one pond 4 hectares in size or greater. Latitudes at which one replicate population came from a smaller pond were northern Ontario, southern Ontario, Virginia, North Carolina and Florida; in no case were both replicates collected from a smaller pond. 


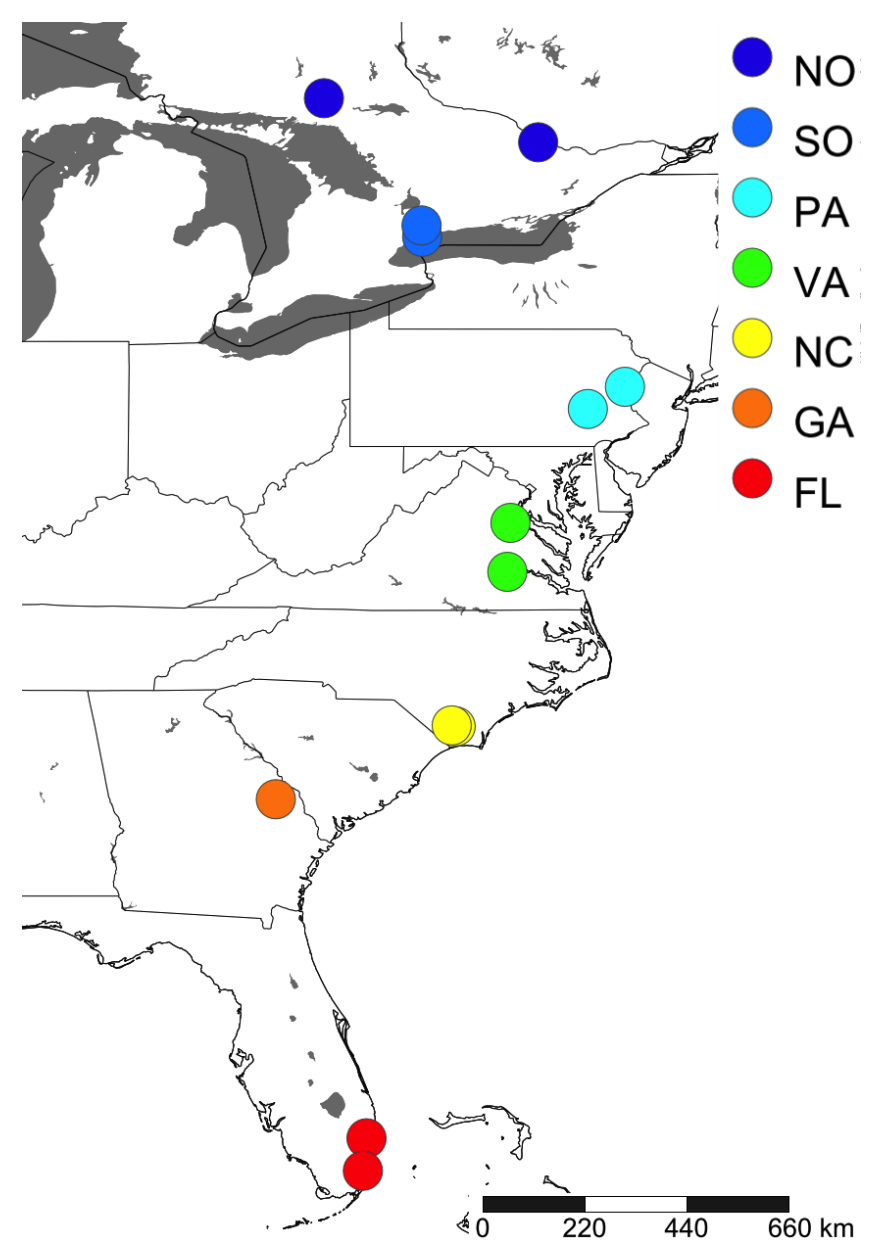

Figure 2.1. S. polyrhiza collection locations. Fronds were collected from 7 latitudes with 2 populations per latitude with the exception of Georgia (1 population) for 13 total populations.

Fronds used in the laboratory study were produced in 12-well plates. Because a mother's own birth order influences timing of daughter turion production (Mejbel \& Simons, 2018) and birth order is unknown in the stock culture, birth order was standardized prior to the study by selecting first birth-order daughters of first birth-order daughters for at least four generations (Barks \& Laird, 2016b). This eliminates both maternal effects and any other environmental effects that may have an influence on timing of turion production. Daughters were separated from their mother upon production of their own first daughter frond. These standardized first birth order daughters were then used to generate third birth order fronds to 
act as the focal mothers in the experiment. However, because these third birth-order daughter fronds begin producing their own daughters prior to detaching from their maternal frond, the introduction of focal mothers to the thermogradient at this stage would mean that their first daughters would not experience thermogradient conditions during a critical phase of development, precluding the possibility of first birth order turion production. Therefore, the standardized first birth order daughters were introduced into the thermogradient (described below) immediately upon initiation of the focal third birth order daughters. The original first birth-order mother fronds were discarded once third birth order focal fronds produced their own first daughters. Standardization was performed at $25^{\circ} \mathrm{C}$ with a $14 \mathrm{~h}$ photoperiod in a Biochambers SG-30 seed germinator. Fronds were maintained on Appenroth's nutrient medium (Appenroth et al., 1996). Twelve-well plate position was randomized within the seed germinator and rotated regularly.

Geographical differences in reaction norms were assessed on a thermogradient incubator (Figure 2.2). Two thermogradient runs were performed. A first run provided useful preliminary information useful for the design of the second run, although problems precluded the use of data for the main results. A discussion of the results for this run are in appendix B. The thermogradient consists of an aquatic chamber, separated into two replicate lanes, mounted on an aluminum block. A water heater and cooler circulate water in a counter current at opposite ends through the aluminum block to produce a temperature gradient, resulting in a corresponding gradient of water temperatures in the aquatic chamber. The aquatic chamber was separated into 6 discrete temperature sections using plexiglass barriers. Four-watt aquarium pumps were used to circulate water within each section to maintain a constant 
temperature. A water temperature range of $10-16^{\circ} \mathrm{C}$ was used (Figure 2.2), based on a test run that showed no turion production in any population above $16^{\circ} \mathrm{C}$. This run also showed that one Florida population expressed no plasticity to temperature at least as low as $12^{\circ} \mathrm{C}$, producing only normal fronds; thus, a colder temperature $\left(10^{\circ} \mathrm{C}\right)$ was included to further accommodate the possibility of turion production by this population.

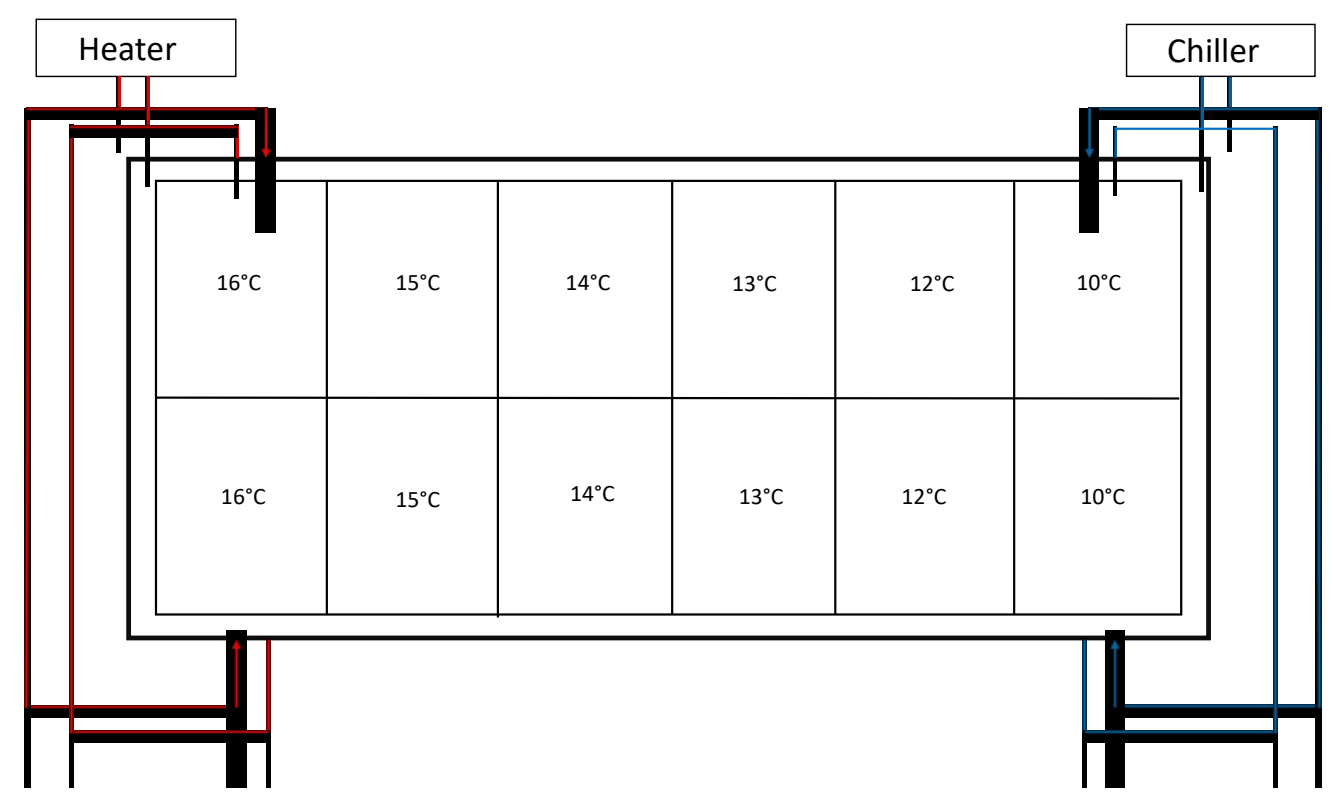

Figure 2.2. Schematic of thermogradient incubator. A heater and chiller circulate warm and cold water through the underlying aluminum block at opposite ends to produce a temperature gradient in the aquatic chamber above. Pumps circulate water to maintain constant temperature within each section of the aquatic chamber. Fronds were placed in tubes in each temperature section.

Eight mother fronds from each latitude (4 for Georgia) were represented at each temperature increment giving a total of 312 fronds ( 2 fronds/population/temperature*2 populations/latitude*7 latitudes*6 temperatures*2 replicates - 1 Georgia population [24 fronds]) for observation of offspring turion production. Mother fronds were housed individually in glass culture tubes held in place by floating rafts made from styrofoam insulation board, which also served to homogenize temperatures within sections and reduce evaporative water 
loss. Frond position within each section was randomized and changed weekly. An overhead fluorescent grow light on a $14 \mathrm{~h}$ photoperiod was used for the duration of the experiment. Duckweed grows well under low light levels (e.g. Vidakovič-Cifrek et al., 2013), and we used a light intensity of approximately $25 \mu \mathrm{mol} \mathrm{m} \mathrm{m}^{-2}$.

Phenology of turion production was monitored daily upon introduction of mother fronds to the thermogradient incubator and assessed in two ways: as first turion birth order, and as days to first turion. First turion birth order is the birth order at which a turion is first produced by a mother frond. For example, if three normal fronds are produced followed by a turion, the turion is scored as birth order four. Daughter fronds were detached from mother fronds once they produced their own first daughter. Turions were removed once they naturally separated from the mother frond.

\subsubsection{Statistical Analysis}

First turion birth order, our primary measure of turion phenology, was analyzed using a type I mixed effects model. The model included main effects of latitude (categorical, fixed) and temperature (continuous) with their interaction; thermogradient lane and population (within latitude) were treated as random effects with lane nested within population and population nested with latitude for a full model of: First turion birth order $=$ latitude + temperature + (latitude*temperature) + population(latitude) + lane(population(latitude)). Significance was assessed using Satterthwaite approximation for main effects because this method is more conservative than typical assessments of significance for mixed models such as likelihood ratio tests (Luke 2017). Likelihood ratio tests (LRT) were used to test for significance in random effects. 
First turion birth order response data were log transformed to improve normality, and linearity of reaction norms. Some fronds exhibited no turion production; however, omitting first turion birth order for these individuals that show the greatest delay in turion production would seriously bias results. Therefore, to include these data points in the analysis, we adopt a conservative approach and scored first turion birth order as one greater than the birth order of the final daughter produced (Mejbel \& Simons, 2018).

Days to first turion was analyzed separately using a second-degree polynomial mixed model. This quadratic fit was used because temperature has a direct effect on physiological processes, resulting in inflated times to first turion production at colder temperatures (see Figure 4). The same variables used in the analysis of first turion birth order (above) were used. For fronds producing no turions, hypothetical days to first turion was considered to be the end of the experiment after all offspring production ceased. All analyses were performed in R.

\subsection{Results}

Temperature and latitude both significantly affected first turion birth order (Table 2.1). First turion birth order was lower at colder temperatures for all latitudes (Figure 3). The effect of temperature on turion formation is highly dependent on latitude and the significant temperature*latitude interaction term (Table 2.1) indicates that norms of reaction differ across latitudes. At cold temperatures (e.g. $10^{\circ}, 12^{\circ}$ and $13^{\circ} \mathrm{C}$ ), most latitudes produce turions at early birth orders. At warmer temperatures, northern latitude populations continue to produce turions at birth order 5 or earlier while southern populations either produce turions very late (birth-orders 6 and above) or produce no turions. This effect, for example, is obvious in Georgia 
and Florida populations at $15^{\circ}$ and $16^{\circ} \mathrm{C}$ while Ontario and Pennsylvania populations continue to produce turions early at the same temperatures (Figure 2.3).

Table 2.1. Effects of variables on log first turion birth order. Main effects use Satterthwaite's method of significance testing and random effects use likelihood ratio tests (LRT).

Main Effects

\begin{tabular}{lccc}
\hline Variable & $D f$ & $F$ & $p$ \\
Latitude & 6 & 23.63 & $<0.01$ \\
Temperature & 1 & 348.76 & $<0.001$ \\
\hline Interaction & 6 & 22.38 & \\
\hline Random Effects & & & $p$ \\
\hline Variable & $D f$ & LRT statistic & $<0.001$ \\
\hline Latitude(Population) & 1 & 12.84 & 1 \\
\hline Population(Lane) & 1 & 0 & \\
\hline
\end{tabular}




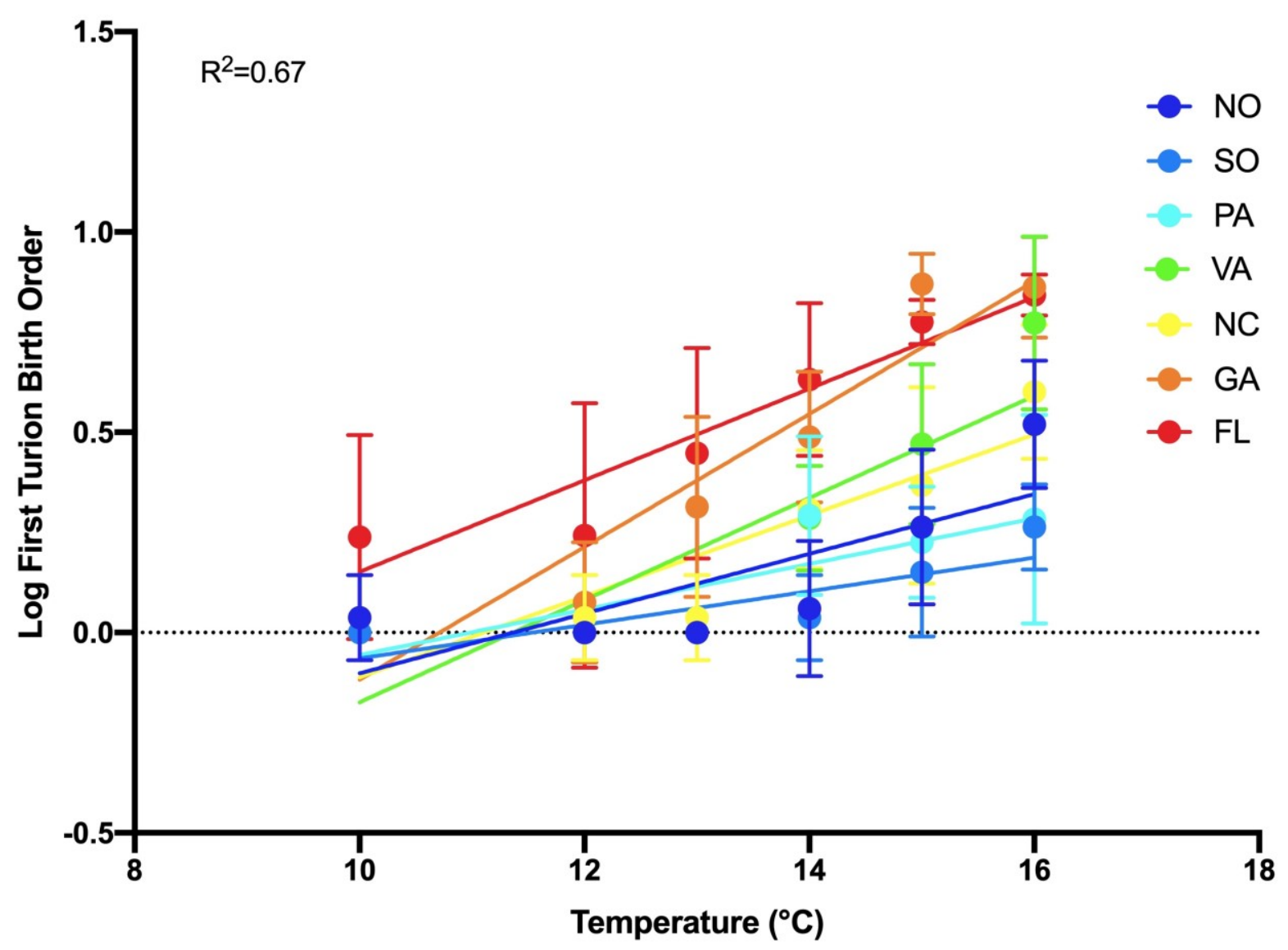

Figure 2.3. Effect of temperature and latitude on log transformed first turion birth order for 13 populations across seven latitudes. $R^{2}$ value is from 2 factor ANCOVA of main effects with interaction for illustration purposes.

Results for days to first turion production, the alternative approach to characterize phenology of turion formation, are similar to those using first turion birth order. Both latitude $\left(F_{1}=27.33, p<0.001\right)$ and the quadratic temperature term $\left(F_{2}=14.21, p<0.001\right)$ were highly significant. Importantly, the interaction term here is also highly significant $\left(F_{2}=8.43, p<0.001\right)$ suggesting reaction norm differentiation. Also, there is clear differentiation in turion timing using this measure such that turions are produced later at southern latitudes (Figure 2.4). 


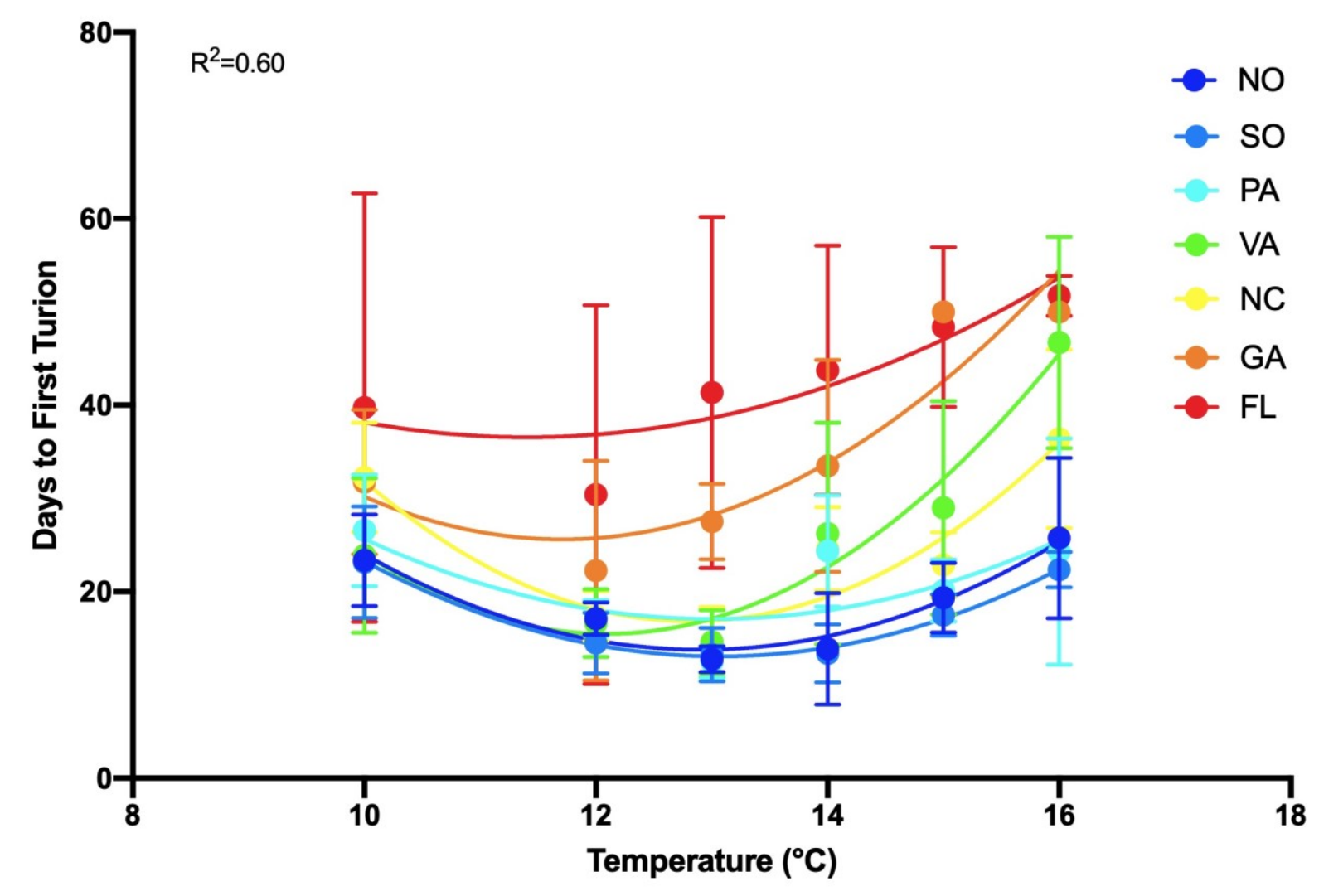

Figure 2.4. Effect of temperature and latitude on time to first turion (days). $R^{2}$ value is from two factor second degree polynomial ANCOVA with interactions for illustration purposes.

The effect of population on time to first turion was small but significant (Table 2.1).

Post-hoc analyses showed a significant difference between the two Florida populations $(p<0.001)$ but no differences between populations from other latitudes. One Florida population exhibits little plasticity to temperature (Figure 2.5), producing few turions regardless of temperature. The slope of the reaction norm for days to first turion in this population does not differ significantly from 0 (Figure $5, \mathrm{p}>0.05$ ). The second Florida population behaves similarly to other southern latitude populations, producing turions early under cold temperatures. Finally, thermogradient lane had no effect on turion timing in either proxy, with its removal improving the model (Table 2.1). 

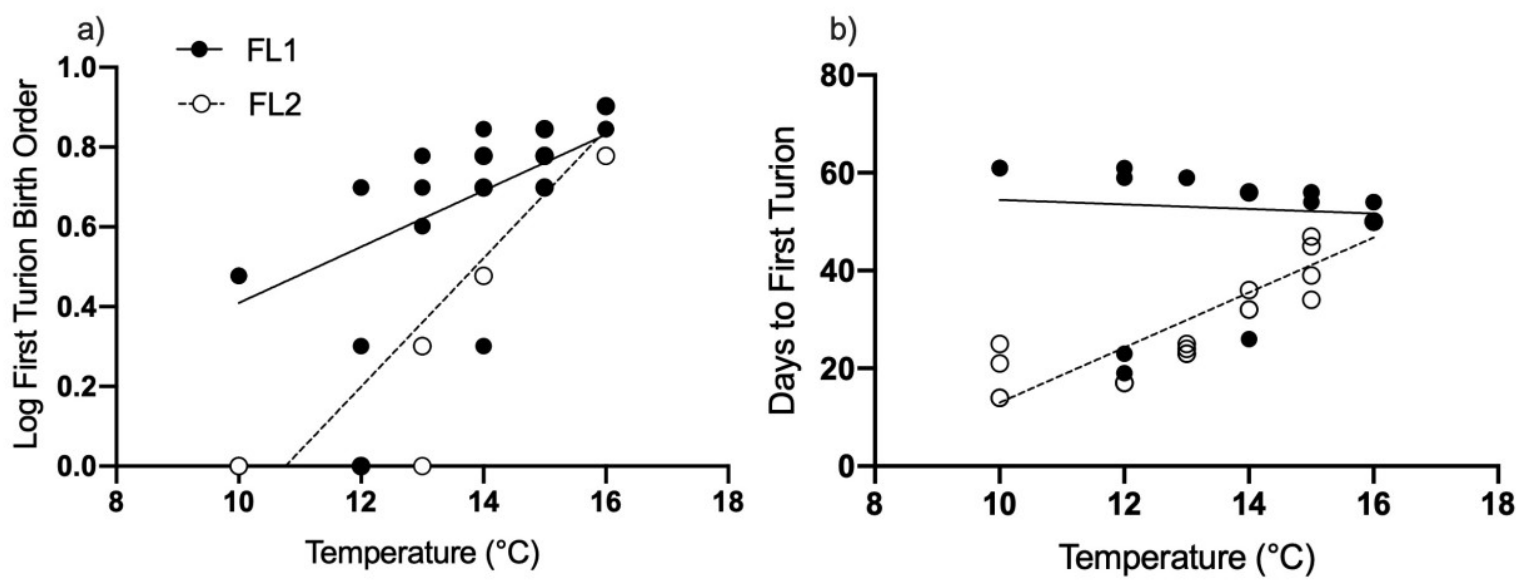

Figure 2.5. Log first turion birth order (a) and days to first turion (b) for both Florida populations, showing reaction norm differentiation between these populations.

\subsection{Discussion}

The occurrence of population differentiation in traits across latitudinal gradients is well established; however, less is known about gradients in plasticity (Gilchrist \& Huey, 2004; Li et al., 2016; Molina-Montenegro et al., 2012; Morin et al., 1999), and even less about latitudinal population differentiation in reaction norms in phenological traits (Kingsolver et al., 2007;

Merilai et al., 2000; Stillwell \& Fox, 2005). Here, we investigated geographic reaction norm differentiation in Greater Duckweed, S. polyrhiza. We predicted reaction norms in turion production would differ across latitudes; specifically, that populations from higher latitudes would produce turions earlier across a common-garden temperature gradient, hypothesizing that more northern populations experience shorter season length and less predictable season termination (Naya et al., 2008; Xu et al., 2017). The finding of a significant effect of latitude of origin on the norm of reaction for phenology of turion production supports this hypothesis. The slopes differ as predicted: populations from Ontario and Pennsylvania produced turions both at an earlier birth order and in a shorter time span than those from southern latitudes such as 
Florida, Georgia and Virginia at warm temperatures, and norms of reaction converge toward colder experimental temperatures (Figure 2.3). This significant interaction between temperature and latitude provides evidence for population differentiation in norms of reaction for a phenological trait-timing of turion production - in response to temperature across latitudes.

Twelve of the thirteen populations studied responded to a temperature cue to initiate turion production. If the temperatures used in the experiment are reliably associated with particular fitness consequences, then plasticity in turion phenology may be adaptive (DeWitt et al., 1998; Reed et al., 2010). Significant differentiation in plasticity of turion phenology was observed at $14^{\circ}$ to $16^{\circ} \mathrm{C}$; northern populations initiated turion production immediately while southern populations delayed production, or produced no turions. This temperature range may reliably indicate imminent growing season termination at northern but not southern latitudes. If this is the case, initiation of turion production in northern populations would increase fitness relative to normal frond growth because it ensures survival over winter, whereas turion production in southern populations would reduce fitness relative to the continuation of normal growth because turions are initially dormant.

The observed differentiation in phenological norms of reaction is consistent with adaptive hypotheses; however, more definitive conclusions about adaptive significance would require further testing. For example, the hypothesis of adaptive divergence in reaction norms across latitudes could be tested using a reciprocal transplant experiment in which the number of surviving fronds in transplanted populations relative to local populations is assessed across seasons at different latitudes. If reaction norms are adaptive, northern populations 
transplanted to a southern latitude should initiate turion production unnecessarily at seasonal low temperatures leaving fewer offspring than native populations, while southern populations transplanted to a northern latitude should initiate turion production late in the season either leaving fewer offspring or risking reproductive failure. Such a reciprocal transplant approach to test local adaptation has been taken in other systems (Ågren \& Schemske, 2012; Bennington et al., 2012; Waser \& Price, 1985).

Populations from all latitudes with the exception of one of two from Florida exhibited plasticity to temperature. For first turion birth order, the reaction norm for this population appears to have a positive slope, producing turions later at higher temperatures. This trend is an artifact of greater normal frond output at higher experimental temperatures (since hypothetical first turions were added at lower daughter birth orders under cold temperatures). Measuring this as days to first turion corrects this and reveals a flat reaction norm, suggesting this population has lost its plastic response to temperature, at least for the temperature range tested.

Interestingly, most populations originating from latitudes that rarely experience pond freeze-over produce turions. It is possible these temperatures fall outside those normally experienced at these latitudes, and there is thus no cost associated with this reaction. Thus, selection would not act directly against this response. Alternatively, turion production at these latitudes may have evolved as a bet-hedging strategy (Seger \& Brockmann, 1987; Simons, 2011) that prevents complete reproductive failure in the event of a rare and unpredictable freezeover. This could occur through a constraint on evolution preventing loss of turion production despite it being maladaptive when low temperatures unnecessarily initiate turion production. 
Though constraints on evolution are well documented, they are generally thought to impede adaptive evolution (Etterson \& Shaw, 2001; Hansen et al., 2003). In the face of unpredictable environmental change, however, a constraint that prevents evolution of a trait that provides short term success but eventual extinction, may itself be adaptive over long timescales (Simons, 2002). In this case, the joint expression of plasticity and bet hedging (e.g. Furness et al., 2015; Simons, 2014) may result in selection for turion production in southern populations.

Bet-hedging may also, in part, explain timing of turion formation at northern latitudes. Environmental variation generally increases with latitude (Molina-Montenegro et al., 2012; Naya et al., 2008; Xu et al., 2017) and consists of predictable and unpredictable components of change (Burgess \& Marshall, 2014; Colwell, 1974). Northern populations may produce turions earlier as a conservative bet-hedging strategy because of higher uncertainty over when the growing season ends. This hypothesis is difficult to test, since earlier turion formation would have to be shown to be adaptive across long time scales (several seasons), despite being suboptimal when an early end to the season does not occur (Simons, 2011). This would require a long-term test of geometric mean fitness with unpredictably timed freezing events that occur at a frequency that is representative of natural conditions across latitudes.

The underlying genetic mechanisms causing differences in sensitivity to temperature across latitudes has yet to be investigated. Because turion production is a plastic trait, it is likely that transcription levels of genes involved in turion production differ across environments, as has been documented in other plastic traits (Gibbons et al., 2017; Lasky et al., 2014; Levine et al., 2010; Schoville et al., 2012; Zhao et al., 2015). In S. polyrhiza, Wang et al (2014b) et al identified 362 genes that are differentially expressed in turion formation induced by abscisic 
acid relative to regular frond formation. These included an increase in expression of ADPglucose phosphorylase genes involved in starch biosynthesis also observed by Wang \& Messing (2012), which are of particular interest since turions function is dependent on high starch storage (Dölger et al., 1997). Evolved changes in expression in these genes may allow populations across latitudes to express different propensities of turion production under the same conditions.

Because of the need to isolate latitude as a source of variation in turion production, we used a standardized maternal birth order. Thus, a limitation of our study is the inability to investigate the combined effects of maternal birth order and latitude. As mentioned, later birth order daughters produce turions earlier in a northern latitude (Ontario) population (Mejbel \& Simons, 2018). Selection may favour greater offspring diversification in northern latitudes where environmental variation is greater. This may result in a positive correlation between latitude and variability of turion phenology across birth orders. There is some evidence of this in frogs in which egg size variability is greater at higher altitudes where environments are less predictable (Chen, Peng, et al., 2018). To test this hypothesis, a design could include early and late (e.g. $3^{\text {rd }}$ and $7^{\text {th }}$ ) birth order daughters, although this would be logistically difficult, requiring multiple thermogradient runs, and staggering of frond introduction times because late birth order daughters are produced after early ones.

Here we provide evidence of geographical reaction norm differentiation in a phenological trait in S. polyrhiza. Populations across different latitudes exhibited different norms of reaction, with more southern populations producing turions later in warmer experimental conditions than northern populations regardless of turion phenology metric. This 
suggests that populations may adapt to different environments through changes in phenotypic plasticity of phenological traits, although the adaptive significance of this finding remains to be tested. These reaction norms may also be explained by the joint expression of plasticity and a conservative bet-hedging strategy, in that turion production occurs earlier in more variable northern latitudes.

\section{References:}

Aesawy, A. M., \& Hasanean, H. M. (1998). Annual and seasonal climatic analysis of surface air temperature variations at six southern Mediterranean stations. Theoretical and Applied Climatology, 61(1-2), 55-68. https://doi.org/10.1007/s007040050051

Ågren, J., \& Schemske, D. W. (2012). Reciprocal transplants demonstrate strong adaptive differentiation of the model organism Arabidopsis thaliana in its native range. New Phytologist, 194(4), 1112-1122. https://doi.org/10.1111/j.1469-8137.2012.04112.x

Aizen, M. A., \& Woodcock, H. (1992). Latitudinal trends in acorn size in eastern North American species of Quercus. Canadian Journal of Botany, 70(6), 1218-1222. https://doi.org/10.1139/b92-153

Anderson, J. T., Inouye, D. W., McKinney, A. M., Colautti, R. I., \& Mitchell-Olds, T. (2012). Phenotypic plasticity and adaptive evolution contribute to advancing flowering phenology in response to climate change. Proceedings of the Royal Society B: Biological Sciences, 279(1743), 3843-3852. https://doi.org/10.1098/rspb.2012.1051

Anderson, J. T., Lee, C. R., \& Mitchell-Olds, T. (2011). Life-history qtls and natural selection on flowering time in boechera stricta, a perennial relative of arabidopsis. Evolution, 65(3), 
771-787. https://doi.org/10.1111/j.1558-5646.2010.01175.x

Ansari, A. A., \& Khan, F. A. (2009). Remediation of eutrophied water using Spirodela polyrrhiza L. Shleid in controlled environment. Pan-American Journal of Aquatic Sciences, 4(1), 52-54.

Appenroth, K. J., Teller, S., \& Horn, M. (1996). Photophysiology of turion formation and germination in Spirodela polyrhiza. Biologia Plantarum, 38(1), 95-106. https://doi.org/10.1007/BF02879642

Appenroth, K., Teller, S., \& Horn, M. (1996). Photophysiology of turion formation and germination in Spirodela polyrhiza. BIOLOGIA PLANTARUM, 38(1), 95-106.

Ashton, K. G. (2002). Patterns of Within-Species Body Size Variation of Birds: Strong Evidence for Bergmann's. Global Ecology and Biogeography, 11(6), 505-523. Retrieved from http://www.jstor.org/stable/3182682

Ashton, K. G., \& Feldman, C. R. (2003). Bergmann's rule in nonavian reptiles: turtles follow it, lizards and snakes reverse it. Evolution, 57(5), 1151-1163. Retrieved from https://onlinelibrary.wiley.com/doi/pdf/10.1111/j.0014-3820.2003.tb00324.x

Ashton, K. G., Tracy, M. C., \& Queiroz, A. de. (2000). Is Bergmann's Rule Valid for Mammals? The American Naturalist, 156(4), 390-415. https://doi.org/10.1086/303400

Ayrinhac, A., Debat, V., Gibert, P., Kister, A.-G., Legout, H., Moreteau, B., ... Kister, ? A.-G. (2004). Cold Adaptation in Geographical Populations of Drosophila melanogaster: Phenotypic Plasticity Is More Important than Genetic Variability. Functional Ecology, 18(5), 700-706. Retrieved from http://www.jstor.org/stable/3599326

Barks, P. M., \& Laird, R. A. (2016a). A multigenerational effect of parental age on offspring size but not fitness in common duckweed (Lemna minor). Journal of Evolutionary Biology, 29(4), 748-756. https://doi.org/10.1111/jeb.12823

Barks, P. M., \& Laird, R. A. (2016b). A multigenerational effect of parental age on offspring size but not fitness in common duckweed (Lemna minor). Journal of Evolutionary Biology, 29(4), 748-756. https://doi.org/10.1111/jeb.12823

Barks, Patrick M, Dempsey, Z. W., Burg, T. M., \& Laird, R. A. (2018). Amoung-strain consistency in the pace and shape of senescence in duckweed. Journal of Ecology, In Press.

Baskin, C. C., Baskin, J. M., \& Chester, E. W. (1999). Seed dormancy in the wetland winter Ptilimnium nuttallii (Apiaceae). Wetlands, 19(2), 359-364. https://doi.org/https://doi.org/10.1007/BF03161767

Bennington, C. C., Fetcher, N., Vavrek, M. C., Shaver, G. R., Cummings, K. J., \& Mcgraw, J. B. (2012). Home site advantage in two long-lived arctic plant species: Results from two 30year reciprocal transplant studies. Journal of Ecology, 100(4), 841-851. 
https://doi.org/10.1111/j.1365-2745.2012.01984.x

Bieleski, R. L. (1968). Effect of Phosphorus Deficiency on Levels of Phosphorus Compounds in Spirodela. Plant Physiology, 43(8), 1309-1316. https://doi.org/10.1104/pp.43.8.1309

Bozinovic, F., Bastías, D. A., Boher, F., Clavijo-Baquet, S., Estay, S. A., \& Angilletta, M. J. (2011). The Mean and Variance of Environmental Temperature Interact to Determine Physiological Tolerance and Fitness. Physiological and Biochemical Zoology, 84(6), 543-552. https://doi.org/10.1086/662551

Burgess, S. C., \& Marshall, D. J. (2014). Adaptive parental effects: The importance of estimating environmental predictability and offspring fitness appropriately. Oikos, 123(7), 769-776. https://doi.org/10.1111/oik.01235

Caicedo, J. R., Van Der Steen, N. P., Arce, O., \& Gijzen, H. J. (2000). Effect of total ammonia nitrogen concentration and $\mathrm{pH}$ on growth rates of duckweed (Spirodela polyrrhiza). Water Research, 34(15), 3829-3835. https://doi.org/10.1016/S0043-1354(00)00128-7

Caldwell, M. M., Robberecht, R., \& Billings, W. D. (1980). A Steep Latitudinal Gradient of Solar Ultraviolet-B Radiation in the Arctic-Alpine Life Zone. Ecology, 61(3), 600-611. https://doi.org/10.2307/1937426

Charmantier, A., McCleery, R. H., Cole, L. R., Perrins, C., Kruuk, L. E. B., \& Sheldon, B. C. (2008). Adaptive phenotypic plasticity in response to climate change in a wild bird population. Science, 320(5877), 800-803. https://doi.org/10.1126/science.1157174

Chen, W., Friesen, C. R., \& Brown, G. P. (2018). Climate change affect reptile community on an island View project Red-Sided Garter Snake Reproductive Energetics View project. Article in Asian Herpetological Research, 2018(1), 43-49. https://doi.org/10.16373/j.cnki.ahr.170073

Chen, W., Peng, L., Jiang, L., Pike, D. A., Friesen, C. R., \& Brown, G. (2018). High altitude frogs (Rana kukonoris) adopt a diversified bethedging strategy in the face of environmental unpredictability. Asian Herpetological Research, 9(1), 43-49. https://doi.org/10.16373/j.cnki.ahr.170073

Childs, D. Z., Metcalf, C. J. E., \& Rees, M. (2010). Evolutionary bet-hedging in the real world: Empirical evidence and challenges revealed by plants. Proceedings of the Royal Society B: Biological Sciences, 277(1697), 3055-3064. https://doi.org/10.1098/rspb.2010.0707

Colwell, R. K. (1974). Predictability, Constancy, and Contingency of Periodic Phenomena. Ecology, 55(5), 1148-1153. https://doi.org/10.2307/1940366

Debieu, M., Tang, C., Stich, B., Sikosek, T., Effgen, S., Josephs, E., ... de Meaux, J. (2013). CoVariation between Seed Dormancy, Growth Rate and Flowering Time Changes with Latitude in Arabidopsis thaliana. PLoS ONE, 8(5), 1-12. 
https://doi.org/10.1371/journal.pone.0061075

DeWitt, T. J., \& Scheinert, S. M. (2004). Phenotypic plasticity: Functional and conceptual approaches. Oxford University Press. https://doi.org/10.1002/ajhb.20088

DeWitt, T. J., Sih, A., \& Wilson, D. S. (1998). Costs and limits of phenotypic plasticity. Trends in Ecology and Evolution, 13(2), 77-81. https://doi.org/10.1016/S0169-5347(97)01274-3

Doğanlar, Z. B. (2013). Metal accumulation and physiological responses induced by copper and cadmium in Lemna gibba, L. minor and Spirodela polyrhiza. Chemical Speciation and Bioavailability, 25(2), 79-88. https://doi.org/10.3184/095422913X13706128469701

Dölger, K., Tirlapur, U. K., \& Appenroth, K. J. (1997). Phytochrome-regulated Starch Degradation in Germinating Turions of Spirodela polyrhiza. Photochemistry and Photobiology, 66(1), 124-127. https://doi.org/10.1111/j.1751-1097.1997.tb03148.x

Donaldson-Matasci, M. C., Bergstrom, C. T., \& Lachmann, M. (2013). When unreliable cues are good enough. American Naturalist, 182(3), 313-327. https://doi.org/10.1086/671161

Dorn, L. A., Pyle, E. H., \& Schmitt, J. (2000). Plasticity to light cues and resources in Arabidopsis thaliana: Testing for adaptive value and costs. Evolution, 54(6), 1982-1994. https://doi.org/10.1111/j.0014-3820.2000.tb01242.x

Edwards, M., \& Richardson, A. J. (2004). Impact of climate change on marine pelagic phenology and trophic mismatch. Nature, 430(7002), 881-884. https://doi.org/10.1038/nature02808

Einum, S., \& Fleming, I. A. (2004). Environmental unpredictability and offspring size: Conservative versus diversified bet-hedging. Evolutionary Ecology Research, 6(3), 443-455. Retrieved from http://www.evolutionary-ecology.com/abstracts/v06n03/jjar1657.pdf

Etterson, J. R., \& Shaw, R. G. (2001). Constraint to adaptive evolution in response to global warming. Science, 294, 151-154. https://doi.org/10.1126/science.1063656

Fleming, I.A., \& Gross, M. R. (1990). Latitudinal Clines : A Trade-Off between Egg Number and Size in Pacific Salmon. Ecology, 71(1), 1-11. https://doi.org/DOI: 10.2307/1940241

Fleming, lan A, \& Gross, M. R. (1990). Latitudinal clines: a trade off between egg number and size in Pacific salmon. Ecology, 71(1), 1-11. Retrieved from http://www.jstor.org/stable/1940241

Footitt, S., Huang, Z., Clay, H. A., Mead, A., \& Finch-Savage, W. E. (2013). Temperature, light and nitrate sensing coordinate Arabidopsis seed dormancy cycling, resulting in winter and summer annual phenotypes. Plant Journal, 74(6), 1003-1015. https://doi.org/10.1111/tpj.12186

Furness, A. I., Lee, K., \& Reznick, D. N. (2015). Adaptation in a variable environment: Phenotypic 
plasticity and bet-hedging during egg diapause and hatching in an annual killifish. Evolution, 69(6), 1461-1475. https://doi.org/10.1111/evo.12669

García-Roger, E. M., Carmona, M. J., \& Serra, M. (2017, July 1). Modes, mechanisms and evidence of bet hedging in rotifer diapause traits. Hydrobiologia, Vol. 796, pp. 223-233. https://doi.org/10.1007/s10750-016-2869-5

Ghalambor, C. K., McKay, J. K., Carroll, S. P., \& Reznick, D. N. (2007). Adaptive versus nonadaptive phenotypic plasticity and the potential for contemporary adaptation in new environments. Functional Ecology, 21, 394-407. https://doi.org/10.1111/j.1365-

2435.2007.01283.x

Gibbons, T. C., Metzger, D. C. H., Healy, T. M., \& Schulte, P. M. (2017). Gene expression plasticity in response to salinity acclimation in threespine stickleback ecotypes from different salinity habitats. Molecular Ecology, 26(10), 2711-2725. https://doi.org/10.1111/mec.14065

Gilchrist, G. W., \& Huey, R. B. (2004). Plastic and Genetic Variation in Wing Loading as a Function of Temperature Within and Among Parallel Clines in Drosophila subobscura 1 (Vol. 44). Retrieved from https://academic.oup.com/icb/article-abstract/44/6/461/610193

Graham, J. K., Smith, M. L., \& Simons, A. M. (2014). Experimental evolution of bet hedging under manipulated environmental uncertainty in Neurospora Crassa. Proceedings of the Royal Society B: Biological Sciences, 281. https://doi.org/10.1098/rspb.2014.0706

Gremer, J. R., \& Venable, D. L. (2014). Bet hedging in desert winter annual plants: optimal germination strategies in a variable environment. Ecology Letters, 17(3), 380-387. https://doi.org/10.1111/ele.12241

Hall, D., Luquez, V., Garcia, V. M., St Onge, K. R., Jansson, S., \& Ingvarsson, P. K. (2007). Adaptive population differentiation in phenology across a latitudinal gradient in European aspen (Populus tremula, L.): A comparison of neutral markers, candidate genes and phenotypic traits. Evolution, 61(12), 2849-2860. https://doi.org/10.1111/j.1558-5646.2007.00230.x

Hansen, T. F., Armbruster, W. S., Carlson, M. L., \& Pélabon, C. (2003). Evolvability and Genetic Constraint in Dalechampia Blossoms: Genetic Correlations and Conditional Evolvability. Journal of Experimental Zoology Part B: Molecular and Developmental Evolution, 296(1), 23-39. https://doi.org/10.1002/jez.b.14

Hillman, W. S. (1961). The Lemnaceae, or duckweeds: A review of the descriptive and experimental literature. The Botanical Review, 27(2), 221-287. https://doi.org/10.1007/BF02860083

Jacobs, D. L. (1947). An Ecological Life-History of Spirodela Polyrhiza (Greater Duckweed) with Emphasis on the Turion Phase. Ecological Monographs, 17(4), 437-469. https://doi.org/10.2307/1948596 
Ji, X., \& Wang, Z.-W. (2005). Geographic variation in reproductive traits and trade-offs between size and number of eggs of the Chinese cobra (Naja atra). Biological Journal of the Linnean Society, 85, 27-40. Retrieved from https://watermark.silverchair.com/j.10958312.2005.00470.x.pdf?token=AQECAHi208BE49Ooan9kkhW_Ercy7Dm3ZL_9Cf3qfKAc485 ysgAAAd0wggHZBgkqhkiG9w0BBwagggHKMIIBxgIBADCCAb8GCSqGSIb3DQEHATAeBglghkg BZQMEAS4WEQQMD-TGAQmdU83fPxBPAgEQgIIBkP1fGs3d9WavYrDe2tJZ5-xyvBJOL4

Jones, P. D., \& Briffa, K. R. (1992). Global surface air temperature variations during the twentieth century: Part 1, spatial, temporal and seasonal details. In The Holocene. https://doi.org/https://doi.org/10.1177/095968369200200208

Jones, T., \& Cresswell, W. (2010). The phenology mismatch hypothesis: are declines of migrant birds linked to uneven global climate change? Journal of Animal Ecology, 79(1), 98-108. https://doi.org/10.1111/j.1365-2656.2009.01610.x

Kellermann, V., Hoffmann, A. A., Overgaard, J., Loeschcke, V., \& Sgro, C. M. (2018). Plasticity for desiccation tolerance across Drosophila species is affected by phylogeny and climate in complex ways. Proceedings of the Royal Society B: Biological Sciences, 285, 20180048. https://doi.org/10.1098/rspb.2018.0048

Kingsolver, J. G., Massie, K. R., Ragland, G. J., \& Smith, M. H. (2007). Rapid population divergence in thermal reaction norms for an invading species: Breaking the temperaturesize rule. Journal of Evolutionary Biology, 20(3), 892-900. https://doi.org/10.1111/j.14209101.2007.01318.x

Klepsatel, P., Gáliková, M., De Maio, N., Huber, C. D., Schlötterer, C., \& Flatt, T. (2013). Variation in thermal performance and reaction norms among populations of drosophila melanogaster. Evolution, 67(12), 3573-3587. https://doi.org/10.1111/evo.12221

Kokita, T. (2003). Potential latitudinal variation in egg size and number of a geographically widespread reef fish, revealed by common-environment experiments. Marine Biology, 143, 593-601. https://doi.org/10.1007/s00227-003-1104-x

Kollmann, J., \& Banuelos, M. J. (2004). Latitudinal Trends in Growth and Phenology of the Invasive Alien Plant Impatiens. Diversity and Distributions, 10(5), 377-385. https://doi.org/https://doi.org/10.1111/j.1366-9516.2004.00126.x

Krajnčič, Božidar, \& Slekovec-Golob, M. (1991). Synergistic Effect of GA3 and EDDHA on the Promotion of Flowering in the Photoperiodically Neutral Plant Spirodela polyrrhiza (L.) Schleiden. Journal of Plant Physiology, 139(2), 240-242. https://doi.org/10.1016/S0176$1617(11) 80615-2$

Krajnčič, Božo, \& Devidé, Z. (1979). Flower development in Spirodela polyrrhiza (Lemnaceae). Plant Systematics and Evolution, 132, 305-312. https://doi.org/10.1007/BF00982392

Laird, R. A., \& Barks, P. M. (2018, December 1). Skimming the surface: duckweed as a model 
system in ecology and evolution. American Journal of Botany, 105(12), 1962-1966. https://doi.org/10.1002/ajb2.1194

Land, J. V., Putten, P. Van, Zwaan, B., Kamping, A., \& Delden, W. Van. (1999). Latitudinal variation in wild populations of Drosophila melanogaster: heritabilities and reaction norms. Journal of Evolutionary Biology, 12(2), 222-232. https://doi.org/10.1046/j.14209101.1999.00029.x

Lankinen, P., Tyukmaeva, V. I., \& Hoikkala, A. (2013). Northern Drosophila montana flies show variation both within and between cline populations in the critical day length evoking reproductive diapause. Journal of Insect Physiology, 59(8), 745-751. https://doi.org/10.1016/j.jinsphys.2013.05.006

Lasky, J. R., Des Marais, D. L., Lowry, D. B., Povolotskaya, I., McKay, J. K., Richards, J. H., ... Juenger, T. E. (2014). Natural variation in abiotic stress responsive gene expression and local adaptation to climate in Arabidopsis thaliana. Molecular Biology and Evolution, 31(9), 2283-2296. https://doi.org/10.1093/molbev/msu170

Laugen, A. T., Laurila, A., Rasanen, K., \& Merila, J. (2003). Latitudinal countergradient variation in the common frog (Rana temporaria) development rates - evidence for local adaptation. J Evol Biol, 16(5), 996-1005. https://doi.org/10.1046/j.1420-9101.2003.00560.x

Lemon, G. D., \& Posluszny, U. (2000). Comparative Shoot Development and Evolution in the Lemnaceae. International Journal of Plant Sciences, 161(5), 733-748. https://doi.org/10.1086/314298

Levine, M. T., Eckert, M. L., \& Begun, D. J. (2011). Whole-genome expression plasticity across tropical and temperate Drosophila melanogaster populations from eastern Australia. Molecular Biology and Evolution, 28(1), 249-256. https://doi.org/10.1093/molbev/msq197

Ley, S., Dölger, K., \& Appenroth, K. J. (1997). Carbohydrate metabolism as a possible physiological modulator of dormancy in turions of Spirodela polyrhiza (L.) Schleiden. Plant Science, 129(1), 1-7. https://doi.org/10.1016/S0168-9452(97)00151-9

Li, B., Suzuki, J. I., \& Hara, T. (1998). Latitudinal variation in plant size and relative growth rate in Arabidopsis thaliana. Oecologia, 115(3), 293-301. https://doi.org/10.1007/s004420050519

Li, J., Du, L., Guan, W., Yu, F. H., \& van Kleunen, M. (2016). Latitudinal and longitudinal clines of phenotypic plasticity in the invasive herb Solidago canadensis in China. Oecologia, 182(3), 755-764. https://doi.org/10.1007/s00442-016-3699-x

Liu, X., \& Yin, Z.-Y. (2000). Spatial and temporal variation of summer precipitation over the eastern Tibetan Plateau and the North Atlantic Oscillation. https://doi.org/10.1175/15200442(2001)014<2896:SATVOS>2.0.CO;2

Liu, X., Yin, Z. Y., Shao, X., \& Qin, N. (2006). Temporal trends and variability of daily maximum 
and minimum, extreme temperature events, and growing season length over the eastern and central Tibetan Plateau during 1961-2003. Journal of Geophysical Research Atmospheres, 111(19), 1-19. https://doi.org/10.1029/2005JD006915

Luke, S.G. 2017. valuating significance in linear mixed-effects models in R. Behavioural Research, 49, 1494-1502

Meiri, S., \& Dayan, T. (2003). On the validity of Bergmann's rule. Journal of Biogeography, 30(3), 331-351. https://doi.org/10.1046/j.1365-2699.2003.00837.x

Mejbel, H. S., \& Simons, A. M. (2018). Aberrant clones: Birth order generates life history diversity in Greater Duckweed, Spirodela polyrhiza. Ecology and Evolution, 8, 2021-2031. https://doi.org/10.1002/ece3.3822

Merilai, J., Laurila, A., Laugen, A. T., Raisainen, K., \& Merili, M. P. (2000). Plasticity in Age and Size at Metamorphosis in Rana Temporaria: Comparison of High and low latitude populations. ECOGRAPHY, 23(23), 457-465. https://doi.org/https://doi.org/10.1111/j.1600-0587.2000.tb00302.x

Moles, A. T., Ackerly, D. D., Tweddle, J. C., Dickie, J. B., Smith, R., Leishman, M. R., ... Westoby, M. (2007). Global patterns in seed size. Global Ecol Biogeography, 16(1), 109-116. https://doi.org/10.1111/j.1466-822x.2006.00259.x

Moles, A. T., \& Westoby, M. (2003). Latitude, Seed Predation and Seed Mass. Journal of Biogeography, 30(1), 105-128.

Molina-Montenegro, M. A., Naya, D. E., \& Seebacher, F. (2012). Latitudinal Patterns in Phenotypic Plasticity and Fitness- Related Traits: Assessing the Climatic Variability Hypothesis (CVH) with an Invasive Plant Species. PLoS ONE, 7(10), e47620. https://doi.org/10.1371/journal.pone.0047620

Morin, J. P., Moreteau, B., Pétavy, G., \& David, J. R. (1999). Divergence of reaction norms of size characters between tropical and temperate populations of Drosophila melanogaster and D. simulans. Journal of Evolutionary Biology, 12(2), 329-339. https://doi.org/10.1046/j.1420-9101.1999.00038.x

Morris, R. S. (2018). Birth order as a source of diversification in spring phenology and its potential effects on performance in greater duckweed, Spirodela polyrhiza.

Mousseau, T. A., \& Roff, D. A. (1989). Adaptation to Seasonality in a Cricket: Patterns of Phenotypic and Genotypic Variation in Body Size and Diapause Expression Along a Cline in Season Length. Evolution, 43(7), 1483-1496. https://doi.org/10.2307/2409463

Naya, D. E., Bozinovic, F., \& Karasov, W. H. (2008). Latitudinal trends in digestive flexibility: Testing the climatic variability hypothesis with data on the intestinal length of rodents. American Naturalist, 172(4), 122-134. https://doi.org/10.1086/590957 
Olsson, K., \& Agren, J. (2002). Latitudinal population differentiation in phenology, life history and flower morphology in the perennial herb Lythrum salicaria. Journal of Evolutionary Biology, 15, 983-996. https://doi.org/10.1046/j.1420-9101.2002.00457.x

Overgaard, J., Kristensen, T. N., Mitchell, K. A., \& Hoffmann, A. A. (2011). Thermal tolerance in widespread and tropical Drosophila species: Does phenotypic plasticity increase with latitude? American Naturalist, 178(SUPPL. 1), 80-96. https://doi.org/10.1086/661780

Parry, D., Goyer, R. A., \& Lenhard, G. J. (2001). Macrogeographic clines in fecundity, reproductive allocation, and offspring size of the forest tent caterpillar Malacosoma disstria. Ecological Entomology, 26(3), 281-291. https://doi.org/10.1046/j.13652311.2001.00319.x

Parry, D., Goyer, R. D., \& Lenard, G. J. (2001). Macrogeographic clines in fecundity, reproductive allocation, and offspring size of the forest tent caterpillar Malacosoma disstria. Ecological Entomology, 26, 281-291. Retrieved from http://www.esf.edu/efb/parry/pubs/parry_etal_2001.pdf

Parsons, S. M. A., \& Joern, A. (2014). Life history traits associated with body size covary along a latitudinal gradient in a generalist grasshopper. Oecologia, 174(2), 379-391. https://doi.org/10.1007/s00442-013-2785-6

Payne, R. B. (1976). The Clutch Size and Numbers of Eggs of Brown-Headed Cowbirds: Effects of Latitude and Breeding Season. The Condor, 78(3), 337-342. Retrieved from http://www.jstor.org/stable/1367693

Pigliucci, M. (2001). Phenotypic Plasticity: Beyond Nature and Nurture. In John Hopkins University Press. https://doi.org/10.1038/sj.hdy.6800153

Platenkamp, G. A. J. (1991). Phenotypic plasticity and population differentiation in seeds and seedlings of the grass Anthoxanthum odoratum. Oecologia, 88(4), 515-520. https://doi.org/10.1007/BF00317714

Posledovich, D., Toftegaard, T., Navarro-Cano, J. A., Wiklund, C., Ehrlén, J., \& Gotthard, K. (2014). Latitudinal variation in thermal reaction norms of post-winter pupal development in two butterflies differing in phenological specialization. Biological Journal of the Linnean Society, 113(4), 981-991. https://doi.org/10.1111/bij.12371

Post, E., \& Forchhammer, M. C. (2008). Climate change reduces reproductive success of an Arctic herbivore through trophic mismatch. Philosophical Transactions of the Royal Society B: Biological Sciences, 363(1501), 2369-2375. https://doi.org/10.1098/rstb.2007.2207

Qiao, X., Shi, G., Jia, R., Chen, L., Tian, X., \& Xu, J. (2012). Physiological and biochemical responses induced by lead stress in Spirodela polyrhiza. Plant Growth Regulation, 67(3), 217-225. https://doi.org/10.1007/s10725-012-9680-8 
Quinn, J. A., \& Wetherington, J. D. (2002). Genetic Variability and Phenotypic Plasticity in Flowering Phenology in Populations of Two Grasses. Journal of the Torrey Botanical Society, 129(2), 96. https://doi.org/10.2307/3088723

Reed, T. E., Robin, S. W., Schindler, D. E., Hard, J. J., \& Kinnison, M. T. (2010). Phenotypic plasticity and population viability: The importance of environmental predictability. Proceedings of the Royal Society B: Biological Sciences, 277(1699), 3391-3400. https://doi.org/10.1098/rspb.2010.0771

Rees, M., Childs, D. Z., Metcalf, J. C., Rose, K. E., Sheppard, A. W., \& Grubb, P. J. (2006). Seed dormancy and delayed flowering in monocarpic plants: selective interactions in a stochastic environment. The American Naturalist, 168(2), 53-71. https://doi.org/10.1086/505762

Riessen, H. P., \& Trevett-Smith, J. B. (2009a). Turning inducible defenses on and off: Adaptive responses of Daphnia to a gape-limited predator. Ecology, 90(12), 3455-3469. https://doi.org/10.1890/08-1652.1

Riessen, H. P., \& Trevett-Smith, J. B. (2009b). Turning inducible defenses on and off: Adaptive responses of Daphnia to a gape-limited predator. Ecology, 90(12), 3455-3469. https://doi.org/10.1890/08-1652.1

Rind, D. (1998). Latitudinal temperature gradients and climate change. Journal of Geophysical Research: Atmospheres, 103, 5943-5971. https://doi.org/10.1029/97JD03649

Rohner, P. T., Roy, J., Schäfer, M. A., Blanckenhorn, W. U., \& Berger, D. (2019a). Does thermal plasticity align with local adaptation? An interspecific comparison of wing morphology in sepsid flies. Journal of Evolutionary Biology, 32(5), 463-475. https://doi.org/10.1111/jeb.13429

Rohner, P. T., Roy, J., Schäfer, M. A., Blanckenhorn, W. U., \& Berger, D. (2019b). Does thermal plasticity align with local adaptation? An interspecific comparison of wing morphology in sepsid flies. Journal of Evolutionary Biology, 32(5), 463-475.

https://doi.org/10.1111/jeb.13429

Santamaria, L., Figuerola, J., Pilon, J. J., Mjelde, M., Green, A. J., De Boer, T., ... Gornall4, A. R. J. (2003). Plant Performance across Latitude: The Role of Plasticity and Local Adaptation in an aquatic plant. Ecology, 84(9), 2454-2461. Retrieved from http://www.jstor.org/stable/3450149

Schmitt, J., McCormac, A. C., \& Smith, H. (1995). A test of the adaptive plasticity hypothesis using transgenic and mutant plants disabled in phytochrome-mediated elongation responses to neighbors. American Naturalist, 146(6), 937-953. https://doi.org/10.1086/285832

Schoville, S. D., Barreto, F. S., Moy, G. W., Wolff, A., \& Burton, R. S. (2012). Investigating the 
molecular basis of local adaptation to thermal stress: Population differences in gene expression across the transcriptome of the copepod Tigriopus californicus. BMC Evolutionary Biology, 12(1). https://doi.org/10.1186/1471-2148-12-170

Schütz, W., Milberg, P., \& Lamont, B. B. (2002). Seed dormancy, after-ripening and light requirements of four annual Asteraceae in south-western Australia. Annals of Botany, 90(6), 707-714. https://doi.org/10.1093/aob/mcf250

Seger, J., \& Brockmann, H. J. (1987). What is bet-hedging? Oxford Surverys in Evolutionary Biology, 4, 182-211.

Siddiqui, W. H., Barlow, C. A., \& Randolph, P. A. (1973). Effects of some constant and alternating temperatures on population growth of the pea aphid, acyrthosiphon pisvm (homoptera: Aphididae). The Canadian Entomologist, 105(1), 145-156. https://doi.org/10.4039/Ent105145-1

Simons, A. M. (2014). Playing smart vs. playing safe: The joint expression of phenotypic plasticity and potential bet hedging across and within thermal environments. Journal of Evolutionary Biology, 27(6), 1047-1056. https://doi.org/10.1111/jeb.12378

Simons, A M, \& Johnston, M. O. (2003). Suboptimal timing of reproduction in Lobelia inflata may be a conservative bet-hedging strategy. Journal of Evolutionary Biology, 16(2), 233243. https://doi.org/10.1046/j.1420-9101.2003.00530.x

Simons, Andrew M. (2002). The continuity of microevolution and macroevolution. Journal of Evolutionary Biology, 15(5), 688-701. https://doi.org/10.1046/j.1420-9101.2002.00437.x

Simons, Andrew M. (2007). Selection for increased allocation to offspring number under environmental unpredictability. Journal of Evolutionary Biology, 20(2), 813-817. https://doi.org/10.1111/j.1420-9101.2006.01270.x

Simons, Andrew M. (2011). Modes of response to environmental change and the elusive empirical evidence for bet hedging. Proceedings of the Royal Society B: Biological Sciences, 278, 1601-1609. https://doi.org/10.1098/rspb.2011.0176

Simovich, M. A., \& Hathaway, S. A. (1997). DIVERSIFIED BET-HEDGING AS A REPRODUCTIVE STRATEGY OF SOME EPHEMERAL POOL ANOSTRACANS (BRANCHIOPODA). Journal of Crustacean Biology, 17(1), 38-44. https://doi.org/10.1163/193724097x00070

Śniegula, S., Nilsson-Örtman, V., \& Johansson, F. (2012). Growth Pattern Responses to Photoperiod across Latitudes in a Northern Damselfly. PLoS ONE, 7(9), e46024. https://doi.org/10.1371/journal.pone.0046024

Stabell, O. B., Ogbebo, F., \& Primicerio, R. (2003). Inducible defences in Daphnia depend on latent alarm signals from conspecific prey activated in predators. Chemical Senses, 28(2), 141-153. https://doi.org/10.1093/chemse/28.2.141 
Stillwell, R. C., \& Fox, C. W. (2005). Complex patterns of phenotypic plasticity: Interactive effects of temperature during rearing and oviposition. Ecology, 86(4), 924-934. https://doi.org/10.1890/04-0547

Su, C., Jiang, Y., Li, F., Yang, Y., Lu, Q., Zhang, T., ... Xu, Q. (2017). Investigation of subcellular distribution, physiological, and biochemical changes in Spirodela polyrhiza as a function of cadmium exposure. Environmental and Experimental Botany, 142, 24-33. https://doi.org/10.1016/j.envexpbot.2017.07.015

Sultan, S. E. (1996). Phenotypic plasticity for offspring traits in Polygonum Persicaria. Ecology, 77(6), 1791-1807. https://doi.org/10.2307/2265784

Tarazona, E., García-Roger, E. M., \& Carmona, M. J. (2017). Experimental evolution of bet hedging in rotifer diapause traits as a response to environmental unpredictability. Oikos, 126(8), 1162-1172. https://doi.org/10.1111/oik.04186

Toftegaard, T., Posledovich, D., Navarro-Cano, J. A., Wiklund, C., Gotthard, K., \& Ehrlén, J. (2016). Variation in plant thermal reaction norms along a latitudinal gradient - more than adaptation to season length. Oikos, 125(5), 622-628. https://doi.org/10.1111/oik.02323

Tyukmaeva, V. I., Salminen, T. S., Kankare, M., Knott, K. E., \& Hoikkala, A. (2011). Adaptation to a seasonally varying environment: A strong latitudinal cline in reproductive diapause combined with high gene flow in Drosophila montana. Ecology and Evolution, 1(2), 160168. https://doi.org/10.1002/ece3.14

Van Kleunen, M., \& Fischer, M. (2005, April). Constraints on the evolution of adaptive phenotypic plasticity in plants. New Phytologist, Vol. 166, pp. 49-60. https://doi.org/10.1111/j.1469-8137.2004.01296.x

Via, S., Gomulkiewicz, R., De Jong, G., Scheiner, S. M., Schlichting, C. D., \& Van Tienderen, P. H. (1995). Adaptive phenotypic plasticity: consensus and controversy. Trends in Ecology \& Evolution, Vol. 10, pp. 212-217. https://doi.org/10.1016/S0169-5347(00)89061-8

Vidakovič-Cifrek, Ž., Sorić, S., \& Babić, M. (2013). Growth and photosynthesis of Lemna minor L. exposed to different light conditions and sucrose supplies. Acta Botanica Croatica, 72(2), 211-219. https://doi.org/10.2478/v10184-012-0018-4

Vitasse, Y., Bresson, C. C., Kremer, A., Michalet, R., \& Delzon, S. (2010). Quantifying phenological plasticity to temperature in two temperate tree species. Functional Ecology, 24(6), 1211-1218. https://doi.org/10.1111/j.1365-2435.2010.01748.x

Wang, W, Haberer, G., Gundlach, H., Gläer, C., Nussbaumer, T., Luo, M. C., ... Messing, J. (2014). The Spirodela polyrhiza genome reveals insights into its neotenous reduction fast growth and aquatic lifestyle. Nature Communications, 5, DOI: 10.1038/ncomms4311 OPEN. https://doi.org/10.1038/ncomms4311 
Wang, Wenqin, \& Messing, J. (2012). Analysis of ADP-glucose pyrophosphorylase expression during turion formation induced by abscisic acid in Spirodela polyrhiza (greater duckweed). BMC Plant Biology, 12(5). https://doi.org/10.1186/1471-2229-12-5

Wang, Wenqin, Wu, Y., \& Messing, J. (2014). RNA-Seq transcriptome analysis of Spirodela dormancy without reproduction. BMC Genomics, 15(1), 60. https://doi.org/10.1186/14712164-15-60

Waser, N. M., \& Price, M. V. (1985). Reciprocal transplant experiments with Delphinum nelsonii (Ranunculaceae): evidence for local adaptation. American Journal of Botany, 72(11), 17261732. https://doi.org/DOI: $10.2307 / 2443730$

Xu, Z., Tang, Y., Connor, T., Li, D., Li, Y., \& Liu, J. (2017). Climate variability and trends at a national scale. Scientific Reports, 7(1), 1-10. https://doi.org/10.1038/s41598-017-03297-5

Yoshifuji, N., Kumagai, T., Tanaka, K., Tanaka, N., Komatsu, H., Suzuki, M., \& Tantasirin, C. (2006). Inter-annual variation in growing season length of a tropical seasonal forest in northern Thailand. Forest Ecology and Management, 229(1-3), 333-339. https://doi.org/10.1016/j.foreco.2006.04.013

Záhorská, E., Baláẑ Ová, M., Bhagat, Y., \& Copp, G. H. (2017). Does latitude drive the phenotypic plasticity of morphological traits in non-native pumpkinseed populations from Europe. Knowledge and Management of Aquatic Ecosystems, 418(29). https://doi.org/10.1051/kmae/2017021

Zhao, L., Wit, J., Svetec, N., \& Begun, D. J. (2015). Parallel Gene Expression Differences between Low and High Latitude Populations of Drosophila melanogaster and D. simulans. PLoS Genetics, 11(5). https://doi.org/10.1371/journal.pgen.1005184

Ziegler, P., Adelmann, K., Zimmer, S., Schmidt, C., \& Appenroth, K. J. (2015). Relative in vitro growth rates of duckweeds (Lemnaceae) - the most rapidly growing higher plants. Plant Biology, 17, 33-41. https://doi.org/10.1111/plb.12184 


\section{Appendices}

Appendix A. Offspring size and number experiment

This experiment was conceived as an analysis of offspring size and number across latitudes to test the prediction that high latitude populations would produce more offspring, potentially as a bet-hedging strategy. This material is included here because it provides some insight into how offspring size differed across latitudes but is not included in the main body of the thesis because premature frond mortality prevented evaluation of the hypothesis. Offspring traits were analyzed at two temperatures in separate growth chambers set to 20 and $25^{\circ} \mathrm{C}$ and a 14h photoperiod. Offspring size was assessed for odd birth order daughters $(1,3,5)$. Photographs were taken upon the maturation of the daughters of these fronds (granddaughters of focal frond) for at least three birth orders. This was to ensure maximum offspring size was recorded as daughter fronds may not have reached full size upon production of their first daughter. Photographs were taken using an Olympus SZX12 microscope with an Infinity 3 Lumenera camera attachment. Measurements were taken using a $0.5 x$ lens at $10 x$ magnification. Offspring size was measured using ImageJ following calibration. Both width and length of fronds were recorded at the longest and widest points of the frond. Length and width were highly correlated $\left(R^{2}=0.85\right)$ so length was used as the main proxy for frond size. Differences in total offspring number between populations could not be determined because excessive algae growth caused premature mortality in the focal fronds.

Preliminary regression analysis showed a weak but significant effect of latitude on offspring size in first $\left(F=5.67, p<0.05, R^{2}=0.07\right)$ and fifth $\left(F=4.47, p<0.05, R^{2}=0.10\right)$ birth order daughters at $25^{\circ} \mathrm{C}$ (Fig. A1). This suggests that frond size may be correlated with latitude at 
some temperatures, but greater power would be needed to determine how strong the relationship is. To determine if size differences were present between populations from different latitudes, offspring size data were analyzed using a three-way ANOVA that included treatment temperature, population and daughter birth order as factors and an interaction between population and temperature. Since correlations between latitudes and offspring size were weak or absent and because size differences may exist within latitudes, population, instead of latitude was used as a factor and was treated as a discrete variable.

(a)



(b)



Figure A1. Correlation between latitude and offspring size in mother birth order 1 (a) and mother birth order 5 (b) both at $25^{\circ} \mathrm{C}$. No significant relationships were observed for any other birth orders at either temperature.

Frond size was found to differ significantly across populations $(F=4.2, p<0.001)$. Post hoc analyses revealed significant differences among a subset of populations (Fig. A2), although no consistent differences are apparent across latitudes. These preliminary results suggest that local environmental conditions may be more important than environmental variables correlated with latitude. Temperature had no effect on offspring size ( $F=0.7, p>0.05)$, but a 
significant effect of mother birth order was observed $(\mathrm{F}=13.94, p<0.05)$. Post-hoc analysis

showed a significant difference between birth orders 3 and $5(p<0.001)$ and 1 and $5(p<0.001)$

but not 1 and $3(p>0.05)$. This is unsurprising given that other studies have shown offspring size in duckweed decreases with birth order (P. M. Barks \& Laird, 2016a; Mejbel \& Simons, 2018).

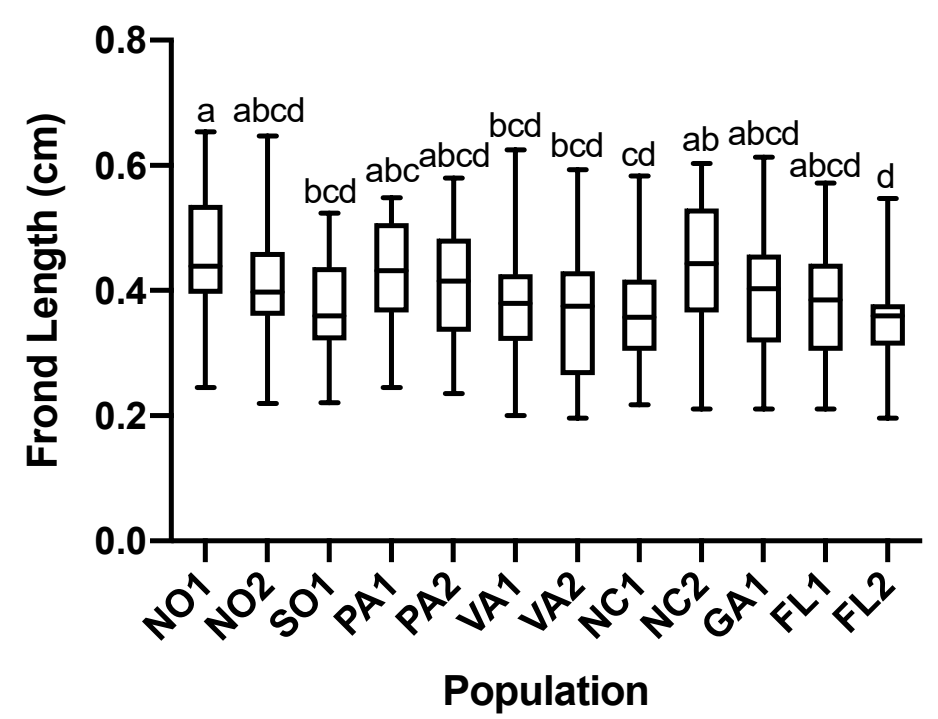

Figure A2. Average frond length for each population.

\section{Appendix B. Initial thermogradient run}

An initial thermogradient run was performed that yielded incomplete results, but that were informative, especially in designing and implementing the run for the main study. In this initial run, two birth order mothers ( 3 and 7 ) were used. Because third and seventh birth order fronds are produced at different times, frond introduction was staggered into two 'batches' of fronds; an early and a late batch. The thermogradient temperatures were not properly balanced at the time of introduction of fronds (Fig. A3). Only one of these temperatures $\left(16^{\circ} \mathrm{C}\right)$ 
was appropriate to assess genetic differentiation in turion production as the others were either too warm, in which case no turions were produced, or too cold in which case only turions were produced, with the exception of a single Florida population (Fig. A4). Data was analyzed as the average turion proportion (the proportion of offspring produced that were turions) at each latitude. This ensures that variation in number of offspring produced in fronds that produced no turions does not influence the results (e.g. a frond that produced 8 daughters but no turions has same turion proportion as one that produced 11 daughters). A mixed model with latitude and temperature as effects and population as a random effect was used.

\begin{tabular}{|l|l|l|l|l|l|l|}
\hline Birth order & 7 & 3 & 7 & 3 & 7 & 3 \\
\hline Lane 1 & 20 & 18.5 & 17.5 & 16 & 14.5 & 12 \\
\hline Lane 2 & 20 & 18.5 & 17.5 & 16 & 14.5 & 12 \\
\hline
\end{tabular}

Figure A3. Schematic of thermogradient set up for first run of experiment. Yellow highlighting shows only temperature at which differentiation in turions production was observed.

Seventh birth order daughters showed no differentiation in timing of turion production between latitudes with the exception of one Florida population, producing no turions at any temperature. This is consistent with the behaviour of this population in the main study. At $16^{\circ} \mathrm{C}$ with third birth order mothers, Ontario populations produced turions earlier than populations from southern latitudes (Fig. A4) but this difference was not significant $\left(d f=12, \chi^{2}=16.55\right.$, $p>0.05)$. The temperature*latitude interaction was also not significant $\left(d f=6, \chi^{2}=6.89, p>0.05\right)$. Temperature, however, did significantly affect turion proportion $\left(d f=7, \chi^{2}=74.35, p<0.05\right)$. 
These results are less reliable than those of the main study for two reasons. First, because temperature was measured differently in the two runs, the " $16^{\circ} \mathrm{C}$ " temperature

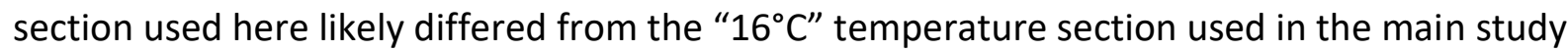
due to differences in temperature calibration. Variation in the temperature probes used to measure thermogradient temperature was observed. To mitigate this effect, one 'master' probe was arbitrarily selected, and the others calibrated to it. As a result, absolute temperatures measured by the probes were likely different between runs though relative temperatures within runs were accurate. The disparity in results likely reflects a warmer temperature used in the first run than in the main study, which would explain why no significant differentiation in turion production was observed, since very little turion production occurred above $16^{\circ} \mathrm{C}$. Second, since differentiation was only observed at one temperature point in the first run, reaction norms could not be reliably assessed. Clear genetic differentiation in turion formation was observed in the main study at several temperature points (chapter 2, Fig. 3) showing clear reaction norm differentiation.

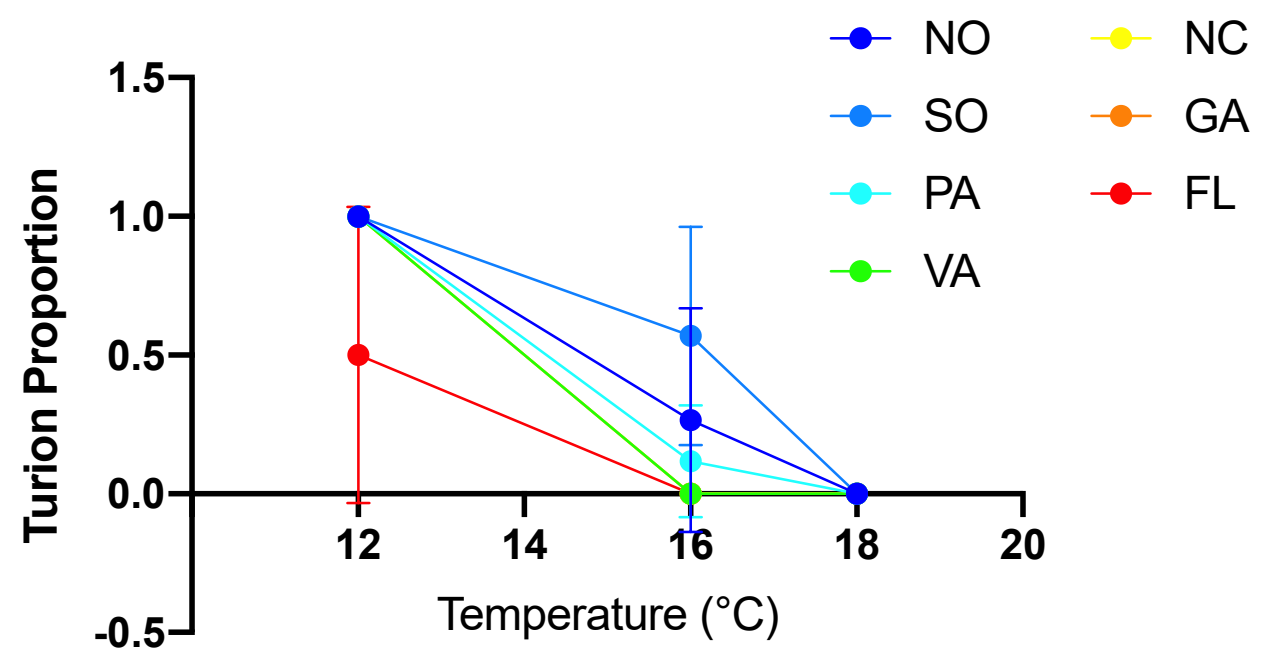

Figure A4. Proportion of offspring produced that were turions for each latitude at three temperatures. 
A logistic regression showed that northern populations are more likely to produce turions than southern populations at $16^{\circ} \mathrm{C}(p<0.05$, Fig A5). There is thus evidence of genetic differentiation in turion production at this temperature, although differentiation in phenology is not detected in this initial run.



Figure A5. Logistic regression of turion production probability vs. latitude at $16^{\circ} \mathrm{C}$. Y-axis indicates whether each frond produced a turion or not. 